\title{
Impacts of the Soil Water Transfer Parameterization on the Simulation of Evapotranspiration over a 14-Year Mediterranean Crop Succession
}

\author{
S. Garrigues, ${ }^{\mathrm{a}}$ A. Boone, ${ }^{\mathrm{b}}$ B. Decharme, ${ }^{\mathrm{b}}$ A. Olioso, ${ }^{\mathrm{a}}$ C. Albergel,${ }^{\mathrm{b}}$ \\ J.-C. CALVET,${ }^{\mathrm{b}}$ S. MOULIN ${ }^{\mathrm{a}}$ S. BUIS, ${ }^{\mathrm{a}}$ AND E. MARTIN ${ }^{\mathrm{b}, \mathrm{c}}$ \\ ${ }^{\text {a }}$ EMMAH, INRA, Université d'Avignon et des Pays de Vaucluse, Avignon, France \\ ${ }^{\mathrm{b}}$ CNRM, UMR3589, Météo-France, CNRS, Toulouse, France \\ ${ }^{\mathrm{c}}$ IRSTEA, UR RECOVER, Aix-en-Provence, France
}

(Manuscript received 4 April 2017, in final form 22 September 2017)

\begin{abstract}
This paper presents a comparison of two water transfer schemes implemented in land surface models: a three-layer bulk reservoir model based on the force-restore scheme (FR) and a multilayer soil diffusion scheme (DIF) relying on explicit mass-diffusive equations and a root profile. The performances of each model at simulating evapotranspiration (ET) over a 14-yr Mediterranean crop succession are compared when the standard pedotransfer estimates versus the in situ values of the soil parameters are used. The Interactions between Soil, Biosphere, and Atmosphere (ISBA) generic land surface model is employed. When the pedotransfer estimates of the soil parameters are used, the best performance scores are obtained with DIF. DIF provides more accurate simulations of soil evaporation and gravitational drainage. It is less sensitive to errors in the soil parameters compared to FR, which is strongly driven by the soil moisture at field capacity. When the in situ soil parameters are used, the performance of the FR simulations surpasses those of DIF. The use of the proper maximum available water content for the plant removes the bias in ET and soil moisture over the crop cycle with FR, while soil water stress is simulated too early and the transpiration is underestimated with DIF. Increasing the values of the root extinction coefficient and the proportion of homogeneous root distribution slightly improves the DIF performance scores. Spatiotemporal uncertainties in the soil parameters generate smaller uncertainties in ET simulated with DIF compared to FR, which highlights the robustness of DIF for large-scale applications.
\end{abstract}

\section{Introduction}

Evapotranspiration (ET) is a key component of the water balance and the energy budget of land surfaces (see Table 1 for definitions of symbols and acronyms). ET plays a key role in the dynamic of land surface feedbacks to the regional climate (Seneviratne et al. 2006) and the dynamic of soil water content (Desborough 1997). ET can be modeled from land surface models (LSMs), which describe the vertical exchange of energy and mass between the soil, vegetation, and atmosphere. LSMs have been designed to be coupled to atmospheric or hydrology models for large-scale studies. Uncertainties in simulated ET can be attributed to two factors: 1) model structure and parameters and 2) errors in the climate and the surface variables used to drive the model and to integrate it

\footnotetext{
Corresponding author: Sébastien Garrigues, sebastien.garrigues@ inra.fr
}

spatially (Vrugt et al. 2009; Garrigues et al. 2015a). In this work, we focus on uncertainties related to the water transfer parameterization, which strongly modulate the plant transpiration and bare soil evaporation components of ET and have been recognized as a major source of departure between land surface models (van den Hurk et al. 2016).

In the first generation of LSMs, water transfers were modeled using bulk soil reservoir schemes. The objective was to design simple models of water transfers with few parameters, which were easily coupled with atmospheric models. In this context, Deardorff (1977) used the force-restore approach, designed by Bhumralkar (1975) and Blackadar (1976) for heat diffusion, to quickly solve soil moisture diffusion equations. In the force-restore scheme, the surface moisture content is forced by the soil evaporation minus precipitation and restored toward the total moisture content of the bulk soil reservoir. The soil is divided into a few reservoirs: 
TABLE 1. Definition of symbols and acronyms.

\begin{tabular}{|c|c|}
\hline BS & Bare soil \\
\hline $\mathrm{C} 3$ & C3 crop \\
\hline $\mathrm{C} 4$ & C4 crop \\
\hline$D$ & Deep drainage \\
\hline DIF & Multilayer soil diffusion scheme \\
\hline$E$ & Soil evaporation $(\mathrm{mm})$ \\
\hline Ecoclimap-II & $\begin{array}{l}\text { Land surface parameter database (spatial reso- } \\
\text { lution of } 1 \mathrm{~km} \text { ) used to run the SURFEX/ISBA } \\
\text { model at global scale (Faroux et al. 2013). }\end{array}$ \\
\hline ET & $\begin{array}{l}\text { Evapotranspiration (cumulative value in } \mathrm{mm} \text { at } \\
\text { daily or multiyear time scales) }\end{array}$ \\
\hline FR & Force-restore water transfer scheme \\
\hline$F_{s, \mathrm{FR}}$ & Stress factors computed in FR [Eq. (2)] \\
\hline$F_{s, \mathrm{DIF}}$ & Stress factors computed in DIF [Eq. (3)] \\
\hline ISBA & $\begin{array}{l}\text { Interactions between Soil, Biosphere, and } \\
\text { Atmosphere (ISBA) LSM }\end{array}$ \\
\hline ISBA-A-gs & $\begin{array}{l}\text { A-gs version of ISBA. A-gs indicates that ISBA } \\
\text { includes a coupled stomatal conductance-- } \\
\text { photosynthesis scheme. }\end{array}$ \\
\hline LAI & Leaf area index $\left(\mathrm{m}^{2} \mathrm{~m}^{-2}\right)$ \\
\hline LE & Latent heat flux $\left(\mathrm{W} \mathrm{m}^{-2}\right)$ \\
\hline MaxAWC & $\begin{array}{l}\text { Maximum available water content. It represents } \\
\text { the maximum root-zone water stock available } \\
\text { for the plant. }\end{array}$ \\
\hline MD & $\begin{array}{l}\text { Mean deviation between simulation and } \\
\text { measurement }\end{array}$ \\
\hline$r$ & Correlation coefficient \\
\hline$R_{e}$ & $\begin{array}{l}\text { Extinction coefficient of the exponential root- } \\
\text { profile model }\end{array}$ \\
\hline$R_{L}$ & $\begin{array}{l}\text { Proportion of homogeneous root distribution in } \\
\text { the root profile }\end{array}$ \\
\hline RMSD & $\begin{array}{l}\text { Root-mean-square difference between simula- } \\
\text { tions and measurements }\end{array}$ \\
\hline SD & Standard deviation \\
\hline SDD & $\begin{array}{l}\text { Standard deviation of the differences between } \\
\text { simulations and measurements }\end{array}$ \\
\hline SURFEX & $\begin{array}{l}\text { "Surface externalisée" in French. SURFEX is } \\
\text { a land and ocean surface platform. }\end{array}$ \\
\hline$T$ & Plant transpiration $(\mathrm{mm})$ \\
\hline$Z_{\text {root-zone }}$ & Rooting depth (m) \\
\hline$\theta_{\mathrm{fc}}$ & $\begin{array}{l}\text { Volumetric soil moisture at field capacity } \\
\left(\mathrm{m}^{3} \mathrm{~m}^{-3}\right)\end{array}$ \\
\hline$\theta_{\text {root-zone }}$ & Root-zone volumetric soil moisture $\left(\mathrm{m}^{3} \mathrm{~m}^{-3}\right)$ \\
\hline & Volumetric soil moisture at saturation $\left(\mathrm{m}^{3} \mathrm{~m}^{-3}\right)$ \\
\hline$\theta_{\mathrm{wp}}$ & $\begin{array}{l}\text { Volumetric soil moisture at the wilting point } \\
\left(\mathrm{m}^{3} \mathrm{~m}^{-3}\right)\end{array}$ \\
\hline
\end{tabular}

a superficial layer that is generally designed to represent the soil evaporation process; a root zone to represent plant water uptake; and, in some models, a deep reservoir to represent the dynamic of deep drainage and to account for upward diffusion. The force-restore models were calibrated using explicit and detailed diffusive models (Noilhan and Planton 1989; Boone et al. 1999). Because of its parsimonious parameterization and reasonable performance scores (Olioso et al. 2002), the force-restore approach was largely used for atmospheric (Manzi and Planton 1994) and hydrology
(Habets et al. 2008) applications. In force-restore, water transfers are simulated according to gradients of moisture content, which can be a reasonable approximation of the matric potential gradient for vertically homogeneous soil. But this approach is not valid for vertically heterogeneous soil profiles, where the relationship between the matric potential and soil moisture can vary vertically (Montaldo and Albertson 2001).

The new generation of LSMs relies on multilayer soil diffusion schemes that explicitly solve the massand heat-diffusive equations (Viterbo and Beljaars 1995; Dai et al. 2003; Decharme et al. 2011). Water transfers are simulated using the Richards equation, which is solved using a discretization of the soil in several layers; this accounts for the vertical gradients in soil texture and structure and the impact of the soil vertical heterogeneity on ET and infiltration (Kutilek and Nielsen 1994). The use of a root profile provides a more realistic representation of a plant's water uptake and response to soil water stress (Desborough 1997; Braud et al. 2005). The multilayer diffusion scheme also improves the representation of soil's freezing processes in cold regions (Habets et al. 2003; Decharme et al. 2016) and heat transfers in dry regions (de Rosnay et al. 2009).

While the multilayer soil diffusion model should represent soil water transfer more realistically, its performance relies on the accurate parameterization of the root profile and vertical distribution of soil hydraulic properties, which may be uncertain at large scales (Desborough 1997; Olioso et al. 2002; Canal et al. 2014). Uncertainties in soil parameters can generate larger uncertainties in ET simulations compared to errors in climate- or vegetation-forcing variables (Garrigues et al. 2015a) or uncertainties in stomatal parameters (Garrigues et al. 2015b).

Garrigues et al. (2015b) have evaluated long time series of ET simulated with the force-restore scheme over a 14-yr Mediterranean crop succession (Avignon, France) that encompasses various types of arable crops interspersed with long intercrop periods for which the ground is bare. This site provides 14 years of continuous measurements of micrometeorological variables, soil moisture, and surface fluxes, which represent a unique opportunity to assess the ET simulations for a large range of surface (soil and vegetation) and atmospheric states. Garrigues et al. (2015b) showed that errors in the standard values of the soil parameters estimated from pedotransfer functions can generate an underestimation of ET of $25 \%$, which represents $\sim 1500 \mathrm{~mm}$ over 12 years. Garrigues et al. (2015b) were mainly focused on the impact of the estimation method used to retrieve the soil parameters (pedotransfer function, laboratory and 
field methods) on ET. This current paper complements and strengthens Garrigues et al.'s (2015b) work by addressing the following questions that have not been investigated for a long crop succession:

- What are the impacts of using the multilayer soil diffusion scheme versus the force-restore scheme on ET and drainage simulations over a 14-yr Mediterranean crop succession?

- How does the root water uptake parameterization influence the simulation of water stress and its impacts on ET?

- How sensitive are the force-restore and the multilayer soil diffusion schemes to errors and uncertainties in the soil parameters?

- What are the benefits and the challenges in using the multilayer soil diffusion scheme versus force-restore for large-scale applications?

We used the Interactions between Soil, Biosphere, and Atmosphere (ISBA) LSM (Noilhan and Planton 1989; Noilhan and Mahfouf 1996) in its A-gs version (coupled photosynthesis-stomatal conductance model) (Calvet et al. 1998). The evaluation was carried out at a local scale over the Avignon Mediterranean crop site used in Garrigues et al. (2015b). To address the above questions, we employed the same methodology developed in Garrigues et al. (2015b). Four experiments were designed using either the force-restore versus the multilayer soil diffusion water transfer scheme or the pedotransfer estimates versus the in situ values of key soil parameters that drive the simulation of ET (soil moisture at saturation, soil moisture at field capacity, and soil moisture at the wilting point). The multilayer soil diffusion experiments were specifically designed for this paper. The force-restore experiments were defined in Garrigues et al. (2015b) over the 2001-12 period. For this work, they were run over a longer period of time (2001-15) for comparison with the multilayer soil diffusion scheme simulations. While only ET and the root-zone soil moisture outputs have been analyzed in Garrigues et al. (2015b), the simulations of drainage were also assessed in this paper.

We first evaluated each experiment against observations. We compared the abilities of the multilayer soil diffusion scheme and the force-restore scheme at simulating ET temporal dynamics over both crop cycles and bare soil periods. We analyzed how errors in the soil parameters affect simulated ET differently, with respect to the type of water transfer model. Differences in rootzone soil moisture and drainage outputs between experiments were investigated. We then conducted a sensitivity analysis of ET to the root profile parameters and computed new values of these parameters for the investigated arable crops. Finally, we quantified and compared the propagation of uncertainties in the soil parameters on ET simulated with each water transfer scheme using Monte Carlo uncertainty analysis. In the discussion, we address the above questions and provide key recommendations for the spatial integration of LSMs.

\section{Site and in situ data}

The description of the site and the associated dataset parallels that of Garrigues et al. (2015b), where detailed site information, site map, measurement protocols, and soil characteristics can be found.

The simulations were evaluated at the Avignon Mediterranean crop site, which is representative of typical Mediterranean cropland. A succession of winter (wheat) and summer (sorghum, maize, sunflower) crops interspersed by intercrop periods has been monitored from April 2001 to March 2015 (Table 2). During intercrop periods, which can last up to nine months, the ground is mostly bare. Summer crops are generally irrigated. Refer to Fig. 2 published in Garrigues et al. (2015b) for an illustration of the crop succession at the Avignon site.

Table 3 provides a summary of the characteristics of the measurements taken at the Avignon site. The measurements include the vegetation and climate variables required to drive LSMs and the estimates of the main outputs of the models (e.g., soil moisture, surface fluxes). All measurements used in this work are assumed to be representative of the field scale. They were derived either from the spatial average of multiple location measurements (e.g., soil moisture, leaf area index) or from spatially integrated measurements (e.g., eddycovariance fluxes, radiation fluxes). They have been continuously monitored since 2001, except the latent heat flux (LE), which has been acquired since 2003.

Estimates of sensible $H$ and latent heat fluxes have been derived from an eddy-covariance system, which is located at the center of the field and provides measurements over a footprint oriented northward in the prevailing wind direction. The eddy-covariance measurements have been processed following the state-of-the-art methodology for croplands, which includes flux corrections (coordinate rotation, density fluctuations, and frequency loss) and detection of spurious fluxes based on footprint and friction velocity thresholds (Beziat et al. 2009; Moureaux et al. 2012). We applied the quality control tests designed by Foken et al. (2004) to select only the best quality class of data for model evaluation (Mauder et al. 2013). We 
TABLE 2. Crop succession, 2001-15. Temperature, rain, and irrigation are the mean temperature, cumulative precipitation, and cumulative irrigation, respectively, over the crop cycle. The table was taken from Garrigues et al. (2015b) and was extended to 2015.

\begin{tabular}{|c|c|c|c|c|c|c|}
\hline Year & Crop & Sowing date & Harvest date & Rain $(\mathrm{mm})$ & Temperature $\left({ }^{\circ} \mathrm{C}\right)$ & Irrigation $(\mathrm{mm})$ \\
\hline 2001 & Maize & 25 Apr 2001 & 28 Sep 2001 & 232.0 & 20.7 & 375 \\
\hline 2002 & Wheat & 23 Oct 2001 & 2 Jul 2002 & 399.0 & 11.6 & 0 \\
\hline 2003 & Sunflower & 16 Apr 2003 & 26 May 2003 & 68.0 & 17.1 & 40 \\
\hline 2003 & Sunflower & 2 Jun 2003 & 19 Sep 2003 & 68.5 & 24.8 & 225 \\
\hline 2004 & Wheat & 7 Nov 2003 & 28 Jun 2004 & 422.0 & 11.2 & 0 \\
\hline 2005 & Peas & 13 Jan 2005 & 22 Jun 2005 & 203.5 & 11.9 & 100 \\
\hline 2006 & Wheat & 27 Oct 2005 & 27 Jun 2006 & 256.0 & 10.7 & 20 \\
\hline 2007 & Sorghum & 10 May 2007 & 16 Oct 2007 & 168.5 & 20.6 & 80 \\
\hline 2008 & Wheat & 13 Nov 2007 & 1 Jul 2008 & 502.5 & 11.7 & 20 \\
\hline 2009 & Maize & 23 Apr 2009 & 15 Jun 2009 & 110.5 & 19.2 & 80 \\
\hline 2009 & Sorghum & 25 Jun 2009 & 22 Sep 2009 & 89.0 & 23.6 & 245 \\
\hline 2010 & Wheat & 19 Nov 2009 & 13 Jul 2010 & 446.5 & 11.6 & 0 \\
\hline 2011 & Sorghum & 22 Apr 2011 & 22 Sep 2011 & 268.5 & 21.4 & 60 \\
\hline 2012 & Wheat & 19 Oct 2011 & 25 Jun 2012 & 437.0 & 12.0 & 0 \\
\hline 2013 & Sunflower & 12 Apr 2013 & 6 Oct 2013 & 262 & 20.0 & 0 \\
\hline 2014 & Wheat & 25 Oct 2013 & 23 Jun 2014 & 466 & 12.4 & 0 \\
\hline
\end{tabular}

apply an additional threshold of $100 \mathrm{~W} \mathrm{~m}^{-2}$ on the energy balance nonclosure to eradicate very inconsistent fluxes with respect to the other components of the energy budget. Garrigues et al. (2015b) have assessed the uncertainties in eddy-covariance measurements by comparing the direct measurements of LE with two other estimates: 1) LE derived as the residue of the energy balance and 2) LE derived from the Bowen ratio. The degree of uncertainty in LE measurements, which is quantified by the standard deviation (SD) of the differences in LE between the direct measurements and the other estimates, falls between 24 and $36 \mathrm{~W} \mathrm{~m}^{-2}$.

The soil characteristics are described in Garrigues et al. (2015b). The soil texture is composed of $33.15 \%$ clay and $13.95 \%$ sand. The vertical variations of the soil texture are low. Not enough observations were available to properly describe the vertical distribution of the soil properties. A homogeneous soil profile was assumed in this work. The soil moisture at saturation $\theta_{s}$ was derived from soil bulk density measurements. The soil moisture at field capacity $\theta_{\mathrm{fc}}$, the soil moisture at the wilting point $\theta_{\mathrm{wp}}$, and the maximum rooting depth $Z_{\text {root-zone }}$ were retrieved from the analysis of the temporal evolution of measured soil moisture vertical profiles over each crop cycle (Garrigues et al. 2015b). For the simulations, we used the mean values of the soil properties that are given in Garrigues et al. (2015b) and are reported in Table 4.

\section{The ISBA-A-gs model}

\section{a. Model description}

In this work, we used the ISBA model (Noilhan and Planton 1989; Noilhan and Mahfouf 1996) embedded in version 8.0 of the "Surface Externalisée" (SURFEX) surface modeling platform (Masson et al. 2013). SURFEX simulates the surface fluxes and their evolution for four types of surfaces: nature, town, inland water, and ocean. ISBA is the LSM used to represent nature surfaces. In ISBA, a single-source energy budget of a soilvegetation composite is computed. In this version of SURFEX, the ISBA parameters are defined for 12 generic land surface patches, which include nine plant functional types (needle leaf trees, evergreen broadleaf trees, deciduous broadleaf trees, C 3 crops, C4 crops, C4 irrigated crops, herbaceous, tropical herbaceous, and wetlands), bare soil, rocks, and permanent snow and ice surfaces. Detailed model descriptions can be found in Masson et al. (2013).

Two distinct schemes can be used to model soil water transfers in ISBA:

- The force-restore scheme (FR) was implemented in the original version of ISBA by Noilhan and Planton (1989). We used the three-reservoir version of force-restore (Boone et al. 1999). The superficial reservoir of thickness $d_{1}=0.01 \mathrm{~m}$ was designed to simulate the soil evaporation and represent the diurnal cycle of the superficial soil moisture. It is restored toward the water content of the root zone, which includes the surface layer. A deep reservoir that extends from the base of the root zone to the total soil-column depth controls the deep drainage flux out the soil column and allows for capillary rise toward the root zone.

- The multilayer soil diffusion scheme (DIF) uses the "mixed" form of the Richards equation to describe the water mass transfer within the soil via Darcy's law (Decharme et al. 2011). The tendency is solved in 
TABLE 3. Characteristics of in situ measurements of the Avignon crop site. Refer to Garrigues et al. (2015b) for a map of the experiment site.

\begin{tabular}{|c|c|c|c|c|}
\hline Variables & $\begin{array}{l}\text { Measurement } \\
\text { characteristics }\end{array}$ & Temporal frequency & Spatial sampling & Processing \\
\hline $\begin{array}{l}\text { Root-zone soil } \\
\text { moisture }\end{array}$ & $\begin{array}{l}0-1.90-\mathrm{m} \text { vertical profile of } \\
\text { soil moisture with a vertical } \\
\text { resolution of } 10 \mathrm{~cm} \\
\text { retrieved from neutron } \\
\text { probes }\end{array}$ & 10 days or fewer & $\begin{array}{l}\text { Three probes spaced } \\
40 \mathrm{~m} \text { apart along } \\
\text { a north-south transect } \\
\text { at the center of the field }\end{array}$ & $\begin{array}{l}\text { Calibration using } \\
\text { gravimetric method } \\
\text { Spatial average } \\
\text { Mean value over the } \\
\text { root-zone profile }\end{array}$ \\
\hline LAI & $\begin{array}{l}\text { Destructive measurements } \\
\text { with planimeter }\end{array}$ & $\begin{array}{l}\text { 5-6 measurements } \\
\text { per crop cycle }\end{array}$ & Four field locations & $\begin{array}{l}\text { Daily interpolation with } \\
\text { degree-day model } \\
\text { Spatial average }\end{array}$ \\
\hline Vegetation height & Meter tape & 10 days & Four field locations & $\begin{array}{l}\text { Daily linear interpolation } \\
\text { Spatial average }\end{array}$ \\
\hline $\begin{array}{l}\text { Air temperature and } \\
\text { humidity, wind speed, } \\
\text { atmospheric pressure }\end{array}$ & $\begin{array}{l}\text { Micrometeorological } \\
\text { station at a } \\
\text { height of } 2 \mathrm{~m} \text { above the } \\
\text { ground or above the } \\
\text { canopy }\end{array}$ & $30 \mathrm{~min}$ & Center of the field & $\begin{array}{l}\text { Quality check } \\
\text { Gap filling }\end{array}$ \\
\hline Precipitation & $\begin{array}{l}\text { Standard meteorological } \\
\text { station }\end{array}$ & $1 \mathrm{~h}$ & $\begin{array}{l}150 \mathrm{~m} \text { apart from the } \\
\text { center of the } \\
\text { field }\end{array}$ & $\begin{array}{l}\text { Quality check } \\
\text { Gap filling }\end{array}$ \\
\hline $\begin{array}{l}\text { Shortwave and long- } \\
\text { wave upwelling and } \\
\text { downwelling } \\
\text { radiation }\end{array}$ & Net radiometer & $30 \mathrm{~min}$ & $\begin{array}{l}\text { Center of the field, } \\
\text { oriented southward }\end{array}$ & $\begin{array}{l}\text { Quality check } \\
\text { Gap filling }\end{array}$ \\
\hline $\begin{array}{l}\text { Latent and sensible heat } \\
\text { fluxes }\end{array}$ & $\begin{array}{l}\text { Eddy-covariance system } \\
\text { (3D sonic anemometer } \\
\text { and open-path gas } \\
\text { analyzer) }\end{array}$ & $30 \mathrm{~min}$ & $\begin{array}{l}\text { Center of the field, } \\
\text { oriented northward in } \\
\text { the prevailing wind } \\
\text { direction }\end{array}$ & $\begin{array}{l}\text { Eddy-covariance standard } \\
\text { corrections } \\
\text { Quality check }\end{array}$ \\
\hline \multirow[t]{2}{*}{ Ground heat flux } & $\begin{array}{l}\text { Ground heat flux retrieved } \\
\text { from heat flux plates at } \\
5 \mathrm{~cm} \text { depth }\end{array}$ & $30 \mathrm{~min}$ & Center of field & Quality check \\
\hline & $\begin{array}{l}\text { Heat storage retrieved from } \\
\text { temperature and soil } \\
\text { moisture probes within } \\
\text { the } 0-5 \text {-cm layer }\end{array}$ & & $\begin{array}{l}\text { One measurement along } \\
\text { the crop row and three } \\
\text { measurements equally } \\
\text { spaced apart in the crop } \\
\text { interrow }\end{array}$ & Spatial average \\
\hline
\end{tabular}

terms of volumetric water, and the hydraulic gradient is solved in terms of water pressure head. In this work, the soil column $(0-12 \mathrm{~m})$ is discretized into $N=18$ layers at depths of $0.010,0.050,0.100,0.200,0.400$, $0.600,0.800,1,1.2,1.4,1.6,1.8,2,2.5,3,5,8$, and $12 \mathrm{~m}$. While the soil hydrology processes are simulated within the first layers $(0-2 \mathrm{~m}$ in this work), the soil column is extended up to $12 \mathrm{~m}$ to ensure a realistic representation of the soil temperature profile (Decharme et al. 2013). Water for soil evaporation is withdrawn from the first layer. Plant water uptake is partitioned in each layer (excluding layer 1 ) of the root zone using a linear combination of an exponential and a homogeneous root-density profile (see appendix).

In both the FR and DIF models, the Clapp and Hornberger (1978) version of the Brooks and Corey (1966) soil water retention model is used. The soil hydraulic parameters are derived from the soil texture using pedotransfer functions built on the Clapp and Hornberger (1978) soil database [see Noilhan and Lacarrère (1995) for FR and Decharme et al. (2011) for DIF]. In force-restore, the soil moisture at field capacity is defined for a hydraulic conductivity of $K=$ $0.1 \mathrm{~mm} \mathrm{day}^{-1}$, while in the diffusive scheme it corresponds to a matric potential of $-3.3 \mathrm{~m}$. This generates differences in the maximum available water content for the plant (MaxAWC; Table 3) defined by

$$
\operatorname{MaxAWC}=Z_{\text {root-zone }}\left(\theta_{\mathrm{fc}}-\theta_{\mathrm{wp}}\right) .
$$

The stomatal conductance used to compute plant transpiration is simulated using the A-gs version of ISBA, which explicitly represents the functional coupling between the stomatal conductance (gs) and the net assimilation of $\mathrm{CO}_{2}$ (A) (Jacobs et al. 1996; Calvet et al. 1998). 
TABLE 4. Characteristics of the experiments. The experiments FR $_{\mathrm{PTF}}$ and $\mathrm{FR}_{\mathrm{LOC}}$ are taken from Garrigues et al. (2015b) while DIF $\mathrm{PTF}_{\mathrm{P}}$ and $\mathrm{DIF}_{\mathrm{LOC}}$ were designed in this study. The experiment $\mathrm{DIF}_{\mathrm{LOC}, \text { opt }}$ is the $\mathrm{DIF}_{\mathrm{LOC}}$ experiment with the optimized values of $R_{e}$ and $R_{L}$; $(\mathrm{C} 3, \mathrm{C} 4)$ refer to the parameter values used for $\mathrm{C} 3$ and $\mathrm{C} 4$ crops.

\begin{tabular}{|c|c|c|c|c|c|}
\hline & $\mathrm{FR}_{\mathrm{PTF}}$ & $\mathrm{DIF}_{\mathrm{PTF}}$ & $\mathrm{FR}_{\mathrm{LOC}}$ & $\mathrm{DIF}_{\mathrm{LOC}}$ & $\mathrm{DIF}_{\text {LOC,opt }}$ \\
\hline $\begin{array}{l}\text { Water transfer } \\
\text { scheme }\end{array}$ & Force-restore & Multilayer soil diffusion & Force-restore & Multilayer soil diffusion & Multilayer soil diffusion \\
\hline $\begin{array}{l}\text { Soil parameter } \\
\text { source }\end{array}$ & Pedotransfer function & Pedotransfer function & In situ & In situ & In situ \\
\hline$\theta_{\text {sat }}\left(\mathrm{m}^{3} \mathrm{~m}^{-3}\right)$ & 0.479 & 0.479 & 0.390 & 0.390 & 0.390 \\
\hline$\theta_{\mathrm{fc}}\left(\mathrm{m}^{3} \mathrm{~m}^{-3}\right)$ & 0.303 & 0.383 & 0.310 & 0.310 & 0.310 \\
\hline$\theta_{\mathrm{wp}}\left(\mathrm{m}^{3} \mathrm{~m}^{-3}\right)$ & 0.214 & 0.214 & 0.184 & 0.184 & 0.184 \\
\hline$Z_{\text {root-zone }}(\mathrm{m})$ & 1.5 & 1.5 & 1.5 & 1.5 & 1.5 \\
\hline MaxAWC (mm) & 134 & 254 & 189 & 189 & 189 \\
\hline$R_{e}(\mathrm{C} 3, \mathrm{C} 4)$ & $0.961,0.972$ & $0.961,0.972$ & $0.961,0.972$ & $0.961,0.972$ & $0.98,0.98$ \\
\hline$R_{L}(\mathrm{C} 3, \mathrm{C} 4)$ & $0.05,0.05$ & $0.05,0.05$ & $0.05,0.05$ & $0.05,0.05$ & $0.75,0.75$ \\
\hline
\end{tabular}

A-gs is based on the photosynthesis model of Goudriaan et al. (1985). The limitation of soil moisture on the plant transpiration is represented by a stress factor $F_{s}$ that quantifies the soil water content available for the plant and varies between 0 (maximum stress) at the wilting point and 1 (no stress) at the field capacity (Calvet et al. 2012). In the force-restore scheme, the soil water stress factor $F_{s, \mathrm{FR}}$ is computed using the bulk root-zone soil water content following:

$$
\begin{aligned}
& \text { if } \theta_{\mathrm{wp}}<\theta_{\text {root-zone }}<\theta_{\mathrm{fc}} F_{s, \mathrm{FR}}=\frac{\theta_{\text {root-zone }}-\theta_{\mathrm{wp}}}{\theta_{\mathrm{fc}}-\theta_{\mathrm{wp}}}, \\
& \text { if } \theta_{\text {root-zone }} \geq \theta_{\mathrm{fc}} F_{s, \mathrm{FR}}=1, \quad \text { and } \\
& \text { if } \theta_{\text {root-zone }} \leq \theta_{\mathrm{wp}} F_{s, \mathrm{FR}}=0 .
\end{aligned}
$$

In the multilayer diffusion scheme, a layer-averaged soil water stress factor $F_{s, \text { DIF }}$ is computed using the rootdensity profile (Pan and Mahrt 1987):

$$
F_{s, \mathrm{DIF}}=\frac{1}{\sum_{i=1}^{N} R_{i}} \sum_{i=1}^{N}\left[\left(\frac{\theta_{i}-\theta_{\mathrm{wp}, i}}{\theta_{\mathrm{fc}, i}-\theta_{\mathrm{wp}, i}}\right)\left(R_{i}\right)\right],
$$

where

$$
\begin{aligned}
& \text { if } \quad \theta_{i} \geq \theta_{f_{c}} \frac{\theta_{i}-\theta_{w p, i}}{\theta_{f c, i}-\theta_{w p, i}}=1 \quad \text { and } \\
& \text { if } \quad \theta_{i} \leq \theta_{w p} \frac{\theta_{i}-\theta_{w p, i}}{\theta_{f c, i}-\theta_{w p, i}}=0 .
\end{aligned}
$$

In Eq. (3), $R_{i}$ is the root fraction in the $i$ th layer, $\theta_{i}$ is the soil water content of the $i$ th layer, $N$ is the number of soil layers within the root zone, and $\theta_{\mathrm{fc}, i}$ and $\theta_{\mathrm{wp}, i}$ are the soil moisture at field capacity and the wilting point of the $i$ th layer, respectively, which are assumed to be constant over the soil profile for this work.

\section{b. Model implementation at the Avignon site}

The model implementation at the Avignon site and the representation of the crop succession in the simulation parallel the approach employed in Garrigues et al. (2015b). Continuous simulations were performed from 25 April 2001 to 1 March 2015. The model is forced by in situ climate observations. The in situ irrigation amount is added to rainfall. In this work, ISBA-A-gs is driven by the 10-day leaf area index (LAI) and vegetation height in situ observations.

The model was run at a 5-min time step, and 30-min outputs of the state variables were analyzed at the model land surface patch scale (C3 crop, C4 crop, bare soil). The 14-yr period was split into subsimulation periods to represent the succession of crop and intercrop periods. To ensure the continuity between two contiguous subsimulations, each subsimulation was initialized using the simulated soil moisture and soil temperature of the last time step of the previous subsimulation.

The simulations were initialized on 25 April 2001 using in situ soil temperatures and soil moisture measurements. For the multilayer soil diffusion scheme, a spinup of 12 years is applied over the 2001-03 period (four loops) to ensure an adequate numerical equilibrium for soil water and temperature profiles. The outputs are analyzed from November 2003 (second wheat cycle).

ISBA only differentiates between $\mathrm{C} 3$ and C4 crops. We used the $\mathrm{C} 3$ crop patch to represent wheat, pea, and sunflower and the $\mathrm{C} 4$ crop patch to represent maize and sorghum. We used the bare soil patch of the model to represent the intercrop periods for which the soil is mostly bare. We explicitly represent the succession of crop and intercrop periods in the simulations by changing the model land surface patch according to the crop succession schedule presented in Table 2.

The root-zone depth was set to $1.5 \mathrm{~m}$, and the total soil column extends to $2 \mathrm{~m}$. These values were derived from 
the analysis of vertical profiles of soil moisture measurements and were proven to generate accurate simulations of surface fluxes and soil moisture in Garrigues et al. (2015b). The values of the rest of the vegetation parameters are provided by the ECOCLIMAP-II database used in the standard implementation of SURFEX (Gibelin et al. 2006; Faroux et al. 2013). The soil parameters are derived from the in situ soil texture of the Avignon site using the pedotransfer functions embedded in the ISBA model. In situ values of soil moisture at saturation, soil moisture at field capacity, and soil moisture at the wilting point are also used in dedicated simulations (see section $4 a$ ).

\section{Methodology}

Different experiments were designed to address the questions raised in the introduction.

\section{a. Experiment design}

\section{1) Evaluation of THE FORCE-RESTORE VERSUS THE MULTILAYER SOIL DIFFUSION SIMULATIONS OF ET}

Two aspects are investigated: the impact of using the multilayer soil diffusion scheme instead of the original force-restore scheme of ISBA, and the interactions between the type of water transfer scheme and errors in the soil parameters. To disentangle the effect of errors in the soil parameters from the effects of the type of water transfer model, we conducted runs using the in situ values of the soil parameters retrieved in Garrigues et al. (2015b) instead of their standard values estimated from the ISBA pedotransfer functions. In the rest of the text, we use the term "local" to refer to in situ soil parameters and simulations achieved with in situ soil parameters. The considered soil parameters are the soil moisture at saturation $\theta_{s}$, the soil moisture at field capacity $\theta_{\mathrm{fc}}$, and the soil moisture at the wilting point $\theta_{\mathrm{wp}}$, which are the main sources of ET uncertainties at the local scale (Garrigues et al. 2015a).

The experiments used to investigate these aspects are defined in Table 4. We used two experiments designed in Garrigues et al. (2015b) for which the simulation period was extended to 2015 :

- $\mathrm{FR}_{\mathrm{PTF}}$ is achieved using the force-restore scheme and the pedotransfer estimates of $\theta_{s}, \theta_{\mathrm{fc}}$, and $\theta_{\mathrm{wp}}$ derived from in situ measurements of soil texture, and

- $\mathrm{FR}_{\mathrm{LOC}}$ is achieved using the force-restore scheme and the local estimates of $\theta_{s}, \theta_{\mathrm{fc}}$, and $\theta_{\mathrm{wp}}$.

Similarly, we designed two new experiments with the multilayer soil diffusion scheme:
- $\mathrm{DIF}_{\mathrm{PTF}}$ is achieved using the multilayer soil diffusion scheme and the pedotransfer estimates of $\theta_{s}, \theta_{\mathrm{fc}}$, and $\theta_{\mathrm{wp}}$, and

- $\mathrm{DIF}_{\mathrm{LOC}}$ is achieved using the multilayer soil diffusion scheme and the local estimates of $\theta_{s}, \theta_{\mathrm{fc}}$, and $\theta_{\mathrm{wp}}$.

The rest of the parameters are identical for all the simulations.

\section{2) SENSITIVITY ANALYSIS TO ROOT PROFILE PARAMETERIZATION}

The goal is to quantify the impact of the root profile parameters on the simulation of ET over the crop succession.

First, we performed two sensitivity analyses of the DIF $_{\text {LOC }}$ simulation to the two key parameters of the root profile used in ISBA [Eqs. (A16) and (A17)]:

- The first parameter is the root extinction coefficient $R_{e}$, which controls the shape of the exponential root profile model. We tested five values spanning the variability range for crops given by Jackson et al. (1996): 0.94, 0.95, 0.96, 0.97, and 0.98. The rest of the parameters are those used in the $\mathrm{DIF}_{\mathrm{LOC}}$ experiment.

- The second parameter is the proportion of homogeneous versus exponential distribution in the root profile $R_{L}$. We tested five values: 0 (fully exponential profile), 0.25, 0.5, 0.75, and 1 (fully homogeneous profile). The rest of the parameters are those used in the $\mathrm{DIF}_{\mathrm{LOC}}$ experiment.

The tested root profiles are displayed in the appendix (Fig. A1).

Then, we optimized $R_{L}$ and $R_{e}$ values for the investigated crops. We performed 25 simulations spanning the range of $R_{L}$ and $R_{e}$ values defined above. We selected the parameter values that provide the lowest RMSE in LE over the crop succession. A new experiment DIF $_{\text {LOC,opt }}$ was run with these optimized parameters (Table 4).

\section{3) UNCERTAINTY ANALYSIS}

The goal is to quantify and compare the impact of uncertainties in the soil parameters on the force-restore versus the multilayer soil diffusion scheme simulations of ET. We applied the same Monte Carlo analysis designed by Garrigues et al. (2015b) for force-restore. We generated an ensemble of 200 ET simulations for the $\mathrm{FR}_{\mathrm{LOC}}$ and $\mathrm{DIF}_{\mathrm{LOC}}$ experiments over the 2004-15 period by applying stochastic perturbations on the soil moisture at saturation, the soil moisture at field capacity, the soil moisture at the wilting point, and the rooting depth. The parameter values are sampled using Gaussian probability distribution functions that represent the 
TABLE 5. Performance scores of simulated LE $(N=198336), \operatorname{ET}_{d}(N=4132)$, and $\theta_{\text {root-zone }}(N=411)$ computed over the $2003-15$ period, where $N$ is the number of samples used to evaluate each variable.

\begin{tabular}{|c|c|c|c|c|c|c|c|c|c|c|c|c|}
\hline & \multicolumn{4}{|c|}{$\mathrm{LE}\left(\mathrm{W} \mathrm{m}^{-2}\right)$} & \multicolumn{4}{|c|}{$\mathrm{ET}_{d}\left(\mathrm{~mm} \mathrm{day}^{-1}\right)$} & \multicolumn{4}{|c|}{$\theta_{\text {root-zone }}\left(\mathrm{m}^{3} \mathrm{~m}^{-3}\right)$} \\
\hline & $r$ & RMSD & MD & SDD & $r$ & RMSD & MD & SDD & $r$ & RMSD & MD & SDD \\
\hline $\mathrm{FR}_{\mathrm{PTF}}$ & 0.79 & 53.54 & -12.50 & 52.05 & 0.77 & 0.88 & -0.26 & 0.85 & 0.79 & 0.04 & 0.03 & 0.03 \\
\hline DIF $_{\text {PTF }}$ & 0.82 & 51.39 & 1.24 & 51.37 & 0.80 & 0.83 & 0.15 & 0.81 & 0.86 & 0.06 & 0.06 & 0.02 \\
\hline $\mathrm{FR}_{\mathrm{LOC}}$ & 0.81 & 54.13 & -0.47 & 54.13 & 0.80 & 0.84 & 0.05 & 0.84 & 0.85 & 0.03 & 0.02 & 0.02 \\
\hline $\mathrm{DIF}_{\mathrm{LOC}}$ & 0.81 & 51.19 & -0.69 & 51.18 & 0.78 & 0.83 & 0.09 & 0.82 & 0.84 & 0.02 & -0.00 & 0.02 \\
\hline $\mathrm{DIF}_{\text {LOC,opt }}$ & 0.83 & 49.39 & 0.79 & 49.39 & 0.82 & 0.79 & 0.12 & 0.78 & 0.86 & 0.02 & -0.01 & 0.02 \\
\hline
\end{tabular}

expected temporal and spatial variability of the soil properties at the field scale. The mean values of the parameters are the values used in $\mathrm{FR}_{\mathrm{LOC}}$ and $\mathrm{DIF}_{\mathrm{LOC}}$ (Table 4), and the standard deviations are given in Garrigues et al. (2015b; Table 8).

\section{b. Evaluation metrics}

The simulations were evaluated against measurements from 7 November 2003 to 1 March 2015, a period over which direct LE measurements were available. The simulation performances were assessed using the correlation coefficient $r$, the root-mean square of the differences between simulations and measurements (RMSD), the mean deviation between simulations and measurements (MD), and the standard deviation of the differences between simulations and measurements (SDD). These metrics were applied to half-hourly LE, daily daytime evapotranspiration $\mathrm{ET}_{d}$, and mean daily root-zone soil moisture $\theta_{\text {root-zone. }}$ Cumulative values of ET were computed over the time steps for which valid ET measurements were available. Values of $\mathrm{ET}_{d}$ were computed when $90 \%$ of daytime measurements were valid for each day. Differences in the cumulative amount and dynamics of gravitational drainage between experiments were also investigated. The performance scores obtained for $\mathrm{FR}_{\mathrm{PTF}}$ and $\mathrm{FR}_{\mathrm{LOC}}$ over the 2004-12 period in Garrigues et al. (2015b) are updated here for the 2004-15 period.

\section{Results}

a. Evaluation of the force-restore and the multilayer
soil diffusion scheme simulations

\section{1) Simulated ET PERFORMANCE SCORES}

Evaluation metrics are reported in Table 5. Figure 1 displays $\mathrm{ET}_{d}$ scatterplots between measurements and simulations.

Correlation between simulations and measurements are of the same order of magnitude for the four experiments. The coefficient of determination (computed as the square of the correlation coefficient) indicates that between $62 \%$ and $67 \%$ of the measured LE variance can be explained by a linear regression between modeled LE and measured LE. FR PTF $_{\text {PTows large underestimation }}$ in $\mathrm{LE}$ and $\mathrm{ET}_{d}$, while the other experiments show low MD with the measurements. When pedotransfer estimates of the soil parameters are used, MD is lower for the DIF experiments than for the FR experiments. The use of local soil parameters nearly removes the MD in $\mathrm{LE}$ and $\mathrm{ET}_{d}$ for the FR simulation but it slightly affects the MD for the DIF simulation. Figure 2 shows that for all experiments, the smallest MDs in LE with measurements are obtained for LAI $=0$, and the largest MDs in LE with measurements are reached at high LAI (2-3). While MD is reduced in $\mathrm{FR}_{\mathrm{LOC}}$ at large LAI, DIF $_{\text {LOC }}$ keeps high MD values at large LAI. The DIF simulations show slightly lower SDD in LE and $\mathrm{ET}_{d}$ than the FR simulations (Table 5). All experiments show larger random scattering (SDD) between simulated LE and measured LE than the level of uncertainty in LE measurements $\left(24-36 \mathrm{~W} \mathrm{~m}^{-2}\right)$ given in section 2.

\section{2) DIFFERENCES IN SIMULATED EVAPOTRANSPIRATION, SOIL EVAPORATION, TRANSPIRATION, AND DRAINAGE BETWEEN EXPERIMENTS}

(i) $E T$

Figure 3 shows that FR $_{\mathrm{PTF}}$ has the lowest cumulative ET over the simulation period. When the pedotransfer soil parameters are used, the $\mathrm{FR}_{\mathrm{PTF}}$ experiment provides lower cumulative ET than the DIF $_{\mathrm{PTF}}$ experiment. When the local soil parameters are used, no differences in cumulative ET are observed between the $\mathrm{FR}_{\mathrm{LOC}}$ and DIF $_{\text {LOC }}$ experiments.

\section{(ii) ET partitioning}

DIF $_{\mathrm{LOC}}$ and $\mathrm{FR}_{\mathrm{LOC}}$ experiments show similar dynamics in plant transpiration $T$ and soil evaporation $E$ over the 14-yr crop succession (Fig. 6). While the cumulative values of ET are similar between the $\mathrm{FR}_{\mathrm{LOC}}$ and DIF $_{\mathrm{LOC}}$ experiments, the level of ET partitioning between $T$ and $E$ is different: cumulative $E$ is larger in 

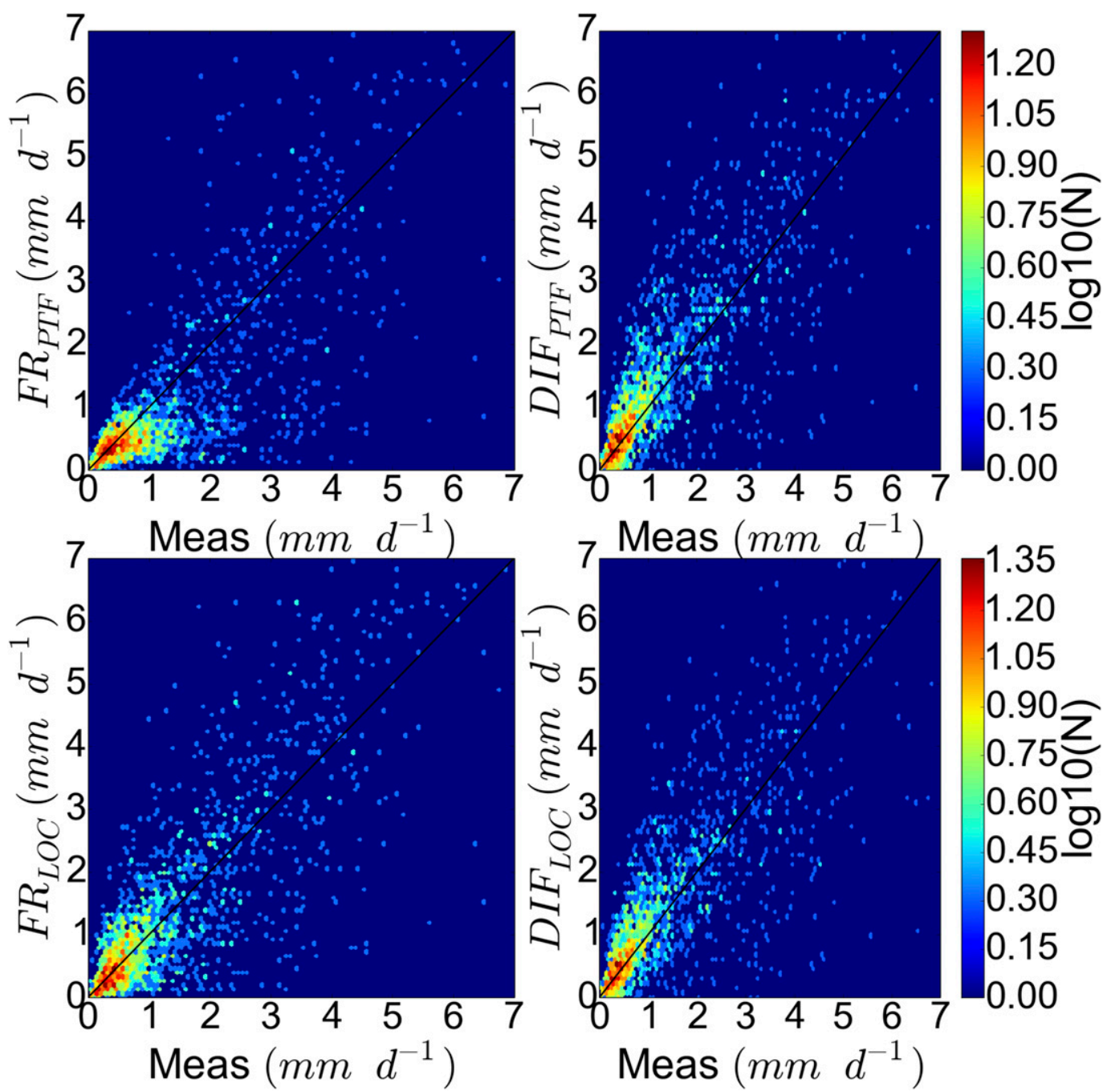

FIG. 1. Scattering in daily ET ( $\mathrm{mm} \mathrm{day}^{-1}$ ) between experiments and measurements (Meas.). In the color bar legend, $N$ is the number of points used to represent the point density.

DIF $_{\text {LOC }}$ than in $\mathrm{FR}_{\mathrm{LOC}}$, while cumulative $T$ is smaller in DIF $_{\text {LOC }}$ than in $\mathrm{FR}_{\text {LOC }}$ (Fig. 3).

\section{(iii) Transpiration}

Figure 3 indicates smaller cumulative transpiration for the DIF experiments than for the FR experiments. When the pedotransfer soil parameters are used, the cumulative transpiration is smaller for $\mathrm{DIF}_{\mathrm{PTF}}$ than for $\mathrm{FR}_{\mathrm{PTF}}$, while MaxAWC is larger in DIF PTF $_{\text {than in }}$ FR $_{\text {PTF }}$ (Table 4). When the local soil parameters are used instead of the pedotransfer estimates, cumulative transpiration increases by $6 \%$ in the $\mathrm{FR}_{\mathrm{LOC}}$ experiment, which is related to an increase in MaxAWC, while it decreases by $7 \%$ in the DIF $_{\text {LOC }}$ experiment, which is related to a drop in MaxAWC (Table 4). The cumulative transpiration is smaller for $\mathrm{DIF}_{\mathrm{LOC}}$ than for $\mathrm{FR}_{\mathrm{LOC}}$ (difference of $326 \mathrm{~mm}, 18 \%$, over 14 years).
Figure $4 \mathrm{a}$ indicates that the decline of transpiration at the end of the crop cycle occurs earlier in the $\mathrm{DIF}_{\mathrm{LOC}}$ experiment than in the $\mathrm{FR}_{\mathrm{LOC}}$ experiment. The depletion of the root-zone soil moisture is larger in the FR $_{\mathrm{LOC}}$ experiment than in the $\mathrm{DIF}_{\mathrm{LOC}}$ simulation (Fig. 4b). While the observed wilting point is reached in $\mathrm{FR}_{\mathrm{LOC}}$, the root-zone soil moisture is overestimated above the prescribed wilting point in $\operatorname{DIF}_{\text {LOC }}$ (Fig. $4 b$ ).

\section{(iv) Soil evaporation}

Figure 3 indicates a larger cumulative soil evaporation for the DIF experiments than for the FR experiments. When the local soil parameters are used instead of the pedotransfer estimates, the cumulative soil evaporation increases by $32 \%$ in the FR experiment and decreases by $2 \%$ in the DIF experiment. Figure 5a shows no differences in simulated soil evaporation between $\mathrm{DIF}_{\mathrm{PTF}}$ and 


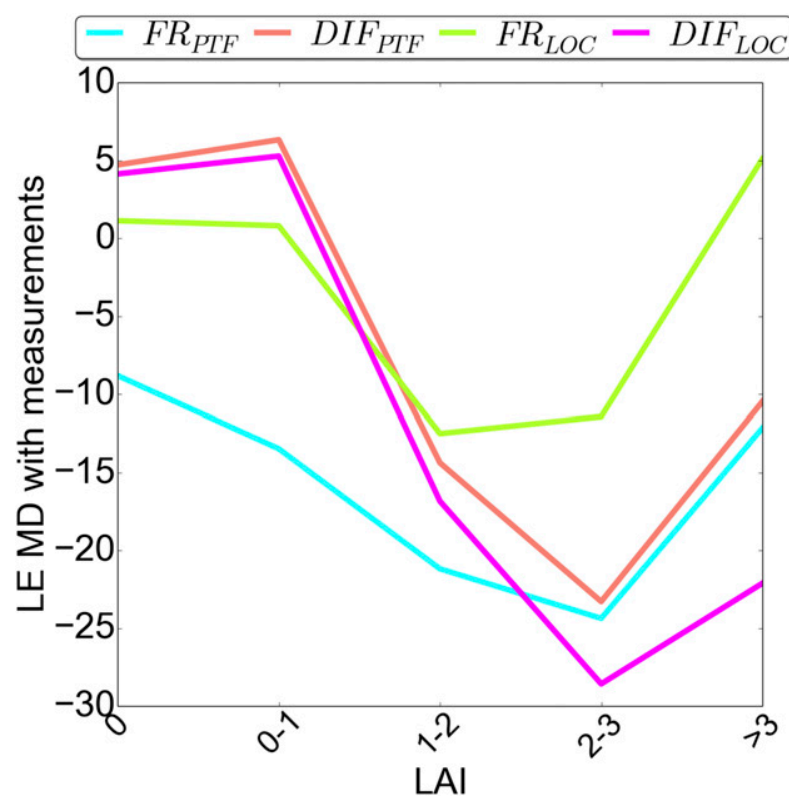

FIG. 2. MD in $\mathrm{LE}\left(\mathrm{W} \mathrm{m}^{-2}\right)$ between each simulation and measurements for different ranges of LAI values.

DIF $_{\text {LOC. }}$ During bare soil periods, the simulated ET and root-zone soil moisture are in better agreement with the measurements for the $\mathrm{DIF}_{\mathrm{LOC}}$ experiment than for the $\mathrm{FR}_{\mathrm{LOC}}$ experiment (Figs. 5a and 5b).

\section{(v) Drainage}

FR $_{\text {PTF }}$ shows the largest cumulative drainage over the simulation period related to the lowest cumulative ET (Fig. 3). The cumulative drainage decreases by $50 \%$ in $\mathrm{FR}_{\mathrm{LOC}}$ compared to $\mathrm{FR}_{\mathrm{PTF}}$. Conversely, the differences in cumulative drainage between DIF $_{\mathrm{PTF}}$ and DIF $_{\text {LOC }}$ are lower ( $20 \%$ over 14 years). The drainage amount simulated in $\mathrm{FR}_{\mathrm{LOC}}$ is comparable to that

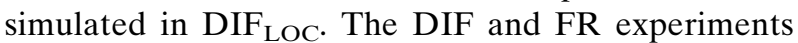
exhibit strong differences in drainage dynamics (Fig. 6). The time evolution of drainage is continuous and slow for the DIF experiments, while it has a staircase behavior and is quicker for the FR experiments (Figs. 4c and 5c).

\section{3) Evaluation of Simulated SOIL MOISTURE}

DIF $_{\mathrm{LOC}}$ shows the lowest MD with measurements for $\theta_{\text {root-zone }}\left(\right.$ Table 5) for bare soil periods (Fig. 5b). FR $_{\mathrm{PTF}}$ and $\mathrm{FR}_{\mathrm{LOC}}$ show large differences in dynamics of $\theta_{\text {root-zone }}$ over both crop and intercrop periods. The depletion of $\theta_{\text {root-zone }}$ over the crop cycle is larger for $\mathrm{FR}_{\mathrm{LOC}}$ than for $\mathrm{FR}_{\mathrm{PTF}}$ (Fig. 4b). During bare soil periods, $\mathrm{FR}_{\mathrm{LOC}}$ frequently shows a steeper decrease in $\theta_{\text {root-zone }}$ than $\mathrm{FR}_{\mathrm{PTF}}$, which is related to larger soil evaporation (e.g., days 299-319 and 74-94 in Figs. 5a and 5b).

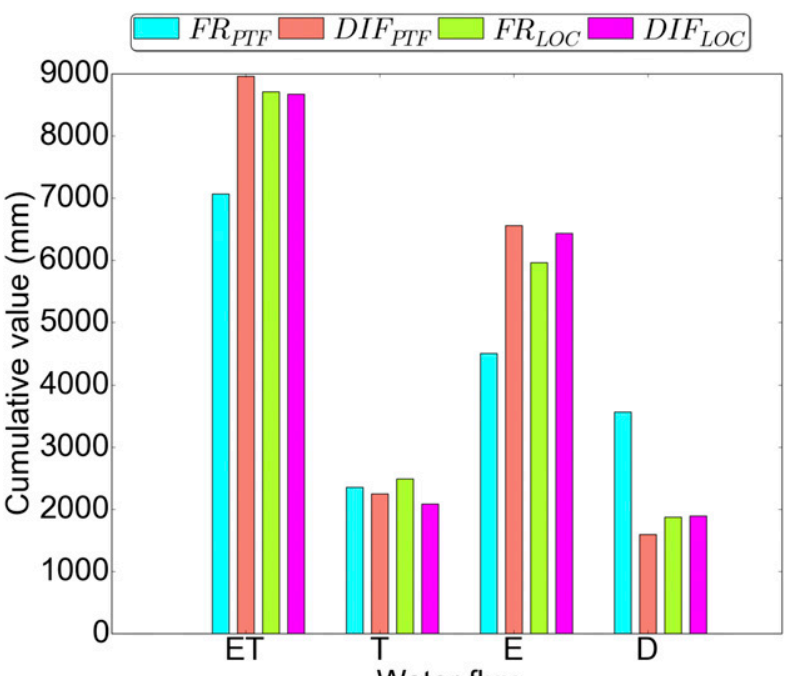

FIG. 3. Cumulative values of $E, T$, and $D$ simulated in each experiment over the 2001-15 simulation period.

\section{4) Evaluation OF STRESS FACTORS}

We compare the stress factors computed in the forcerestore scheme $F_{s, \mathrm{FR}}$ [Eq. (2)] and the multilayer soil diffusion scheme $F_{s, \text { DIF }}$ [Eq. (3)]. Figure 7 displays the time evolution of the differences in the stress factors and in transpiration between $\mathrm{DIF}_{\mathrm{LOC}}$ and $\mathrm{FR}_{\mathrm{LOC}}$ over the 14-yr period. It shows that at the maximum LAI of the crop cycle, the simulated transpiration is frequently smaller for $\mathrm{DIF}_{\mathrm{LOC}}$ than for $\mathrm{FR}_{\mathrm{LOC}}$, which is related to lower values of $F_{s, \mathrm{DIF}}$ (higher stress) than $F_{s, \mathrm{FR}}$.

\section{$b$. Sensitivity analysis to the root profile parameterization}

\section{1) SEnsitivity TO THE ROOT EXTINCTION COEFFICIENT}

Figure 8 shows that transpiration and depletion of $\theta_{\text {root-zone }}$ increase with increasing values of the root extinction coefficient $R_{e}$. Over the 14 -yr crop succession, cumulative transpiration increases by $8 \%$ by increasing $R_{e}$ from 0.96 to 0.98 and decreases by $5 \%$ by reducing $R_{e}$ from 0.96 to 0.94 . However, the differences in transpiration remain important between the $\mathrm{DIF}_{\mathrm{LOC}}$ experiment conducted with the largest $R_{e}$ value and $\mathrm{FR}_{\mathrm{LOC}}(12 \%$ over 14 years).

\section{2) SEnSitivity to THE PROPORTION OF HOMOGENEOUS ROOT DISTRIBUTION}

Figure 9 shows that transpiration increases with increasing values of the proportion of homogeneous root distribution $R_{L}$. Root-zone soil moisture reaches the observed wilting point for $R_{L}=50 \%$. Above $R_{L}=50 \%$, 
a)

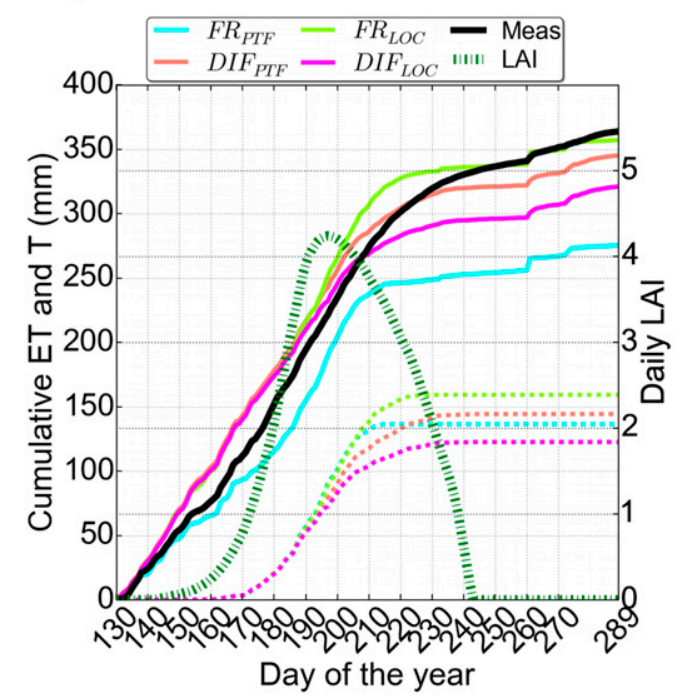

c)

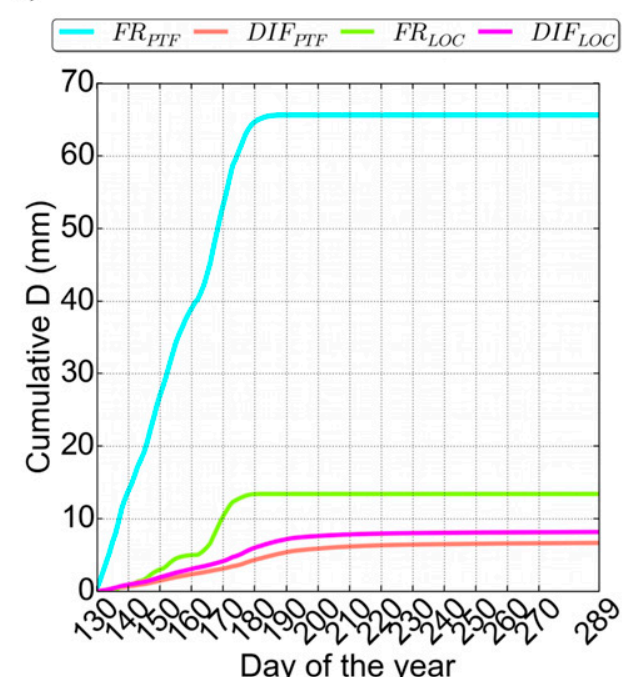

b)

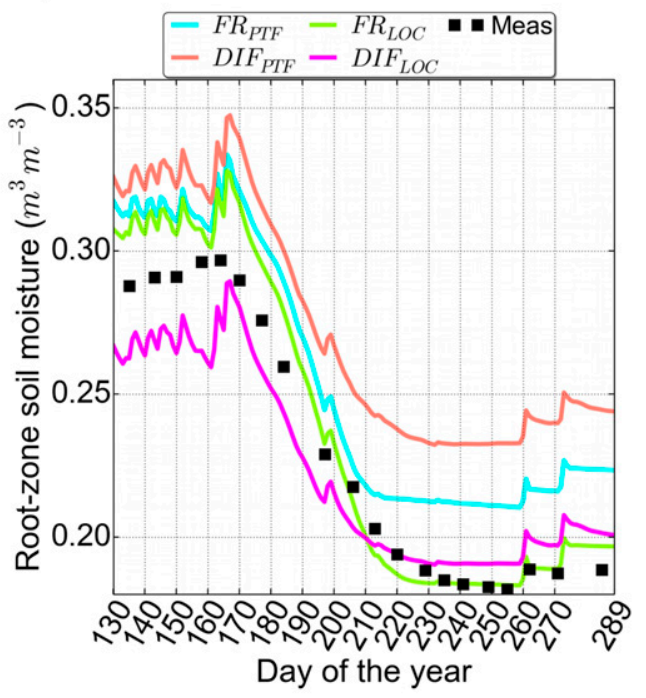

FIG. 4. Evolution of (a) measured and simulated ET, (b) measured and simulated $\theta_{\text {root-zone }}$ and (c) simulated $D$ over the sorghum cycle in 2007. In (a), simulated $T$ is represented by dashed lines, and ET is represented by solid lines. The LAI cycle is represented by green dash-dotted lines.

the increase in transpiration is not significant for most crop cycles. Over the 14-yr crop succession, cumulative transpiration increases by $10 \%$ when a complete homogeneous root distribution $\left(R_{L}=100 \%\right)$ is used instead of the $5 \%$ standard value. However, this leads to lower transpiration than that simulated by $\mathrm{FR}_{\mathrm{LOC}}$ (difference of $8 \%$ over 14 years).

\section{3) Optimization of $R_{E}$ AND $R_{L}$}

The optimized values of $R_{L}$ and $R_{e}$ are 0.75 and 0.98 , respectively (Table 4 ). These values slightly increase the correlation and decrease the dispersion between the measurements compared to $\mathrm{DIF}_{\mathrm{LOC}}$ and $\mathrm{FR}_{\mathrm{LOC}}$ (Table 5).

\section{c. Propagation of soil parameter uncertainties on ET predictions}

Figures 10a and 10b display the ensemble of the Monte Carlo simulations and the associated 95thpercentile interval generated by perturbing the soil parameters in $\mathrm{DIF}_{\mathrm{FR}}$ and $\mathrm{DIF}_{\mathrm{LOC}}$, respectively. For force-restore, the 95th-percentile interval represents $962 \mathrm{~mm}(23 \%)$ of cumulative ET over 11 years, which is of the same order as the value found by Garrigues et al. (2015b) over the 2004-12 period with an ensemble of 100 simulations. For the multilayer soil diffusion scheme, it represents $374 \mathrm{~mm}(9 \%)$ of cumulative ET over 11 years. 
a)

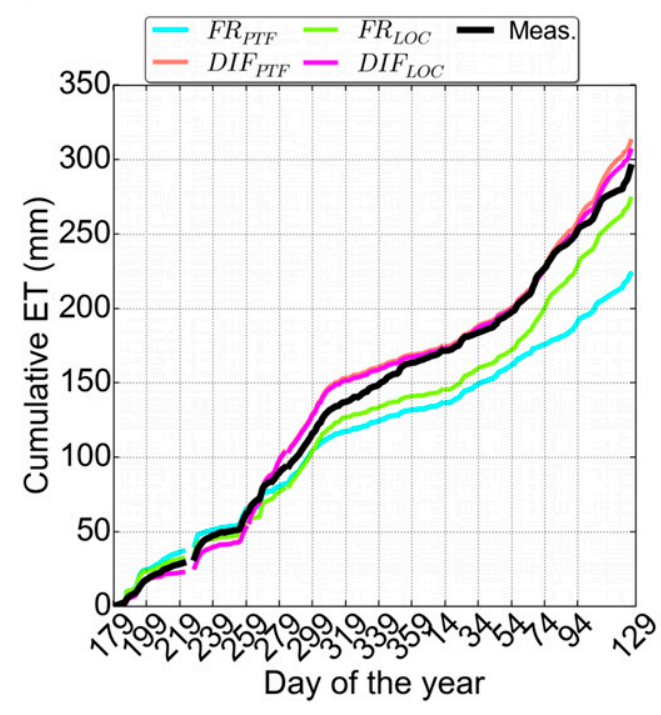

c)

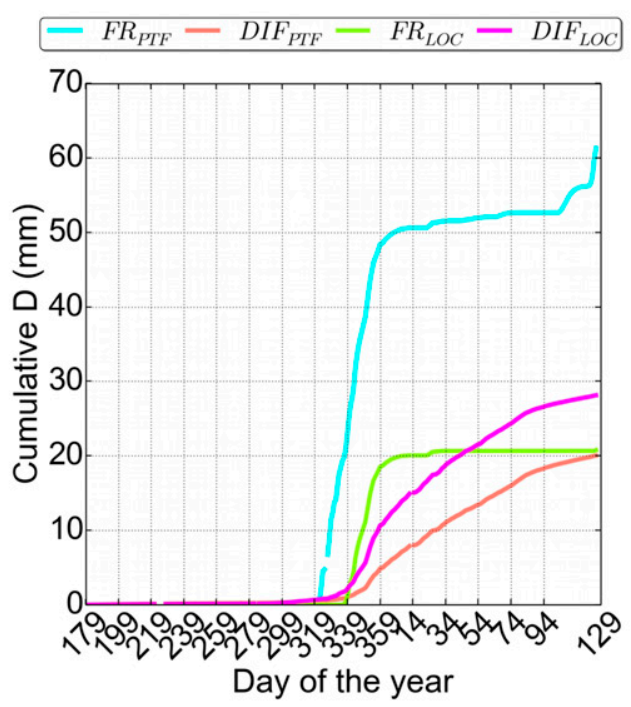

b)

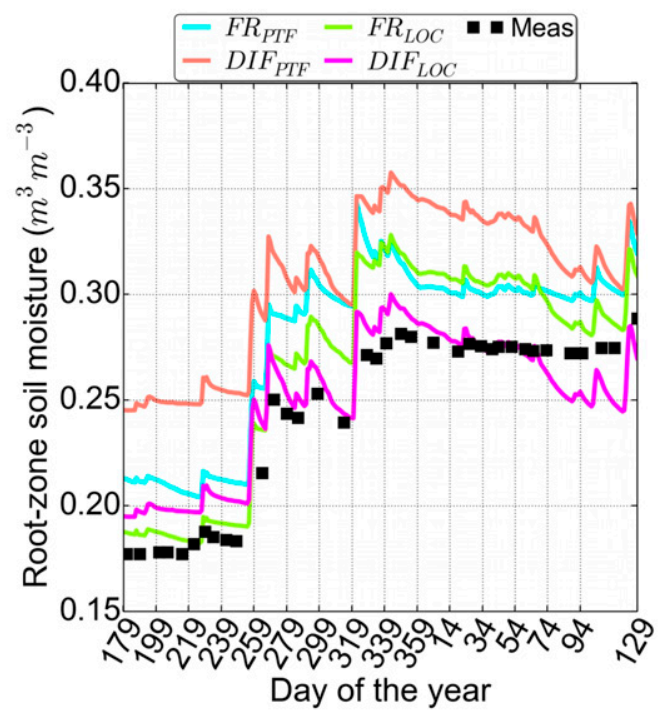

FIG. 5. As in Fig. 4, but for the 2006 intercrop period (BS). ET corresponds to the soil evaporation because the soil is bare.

\section{Discussion}

a. What are the impacts of using DIF versus FR on ET and drainage simulations over a 14-yr Mediterranean crop succession?

1) REPRESENTATION OF THE DYNAMICS OF THE WATER BALANCE COMPONENTS OVER THE CROP SUCCESSION

For all experiments, the amount of simulated surface runoff is very low and can thus be neglected in the water balance; this is mainly driven by ET and drainage for the Avignon site.
The dynamics of ET components simulated with the multilayer soil diffusion scheme presented in Fig. 6 are similar to the dynamics obtained with force-restore in Garrigues et al. (2015b). While plant transpiration provides large fluxes during short periods of time (February-May for winter crops and May-August for summer crops), soil evaporation generates smaller but steadier fluxes. Our study reinforces a major finding from Garrigues et al. (2015b), showing that ET is dominated by soil evaporation, which is the main source of uncertainty over a Mediterranean crop succession.

The simulated drainage mainly occurs during major rain events, which concern short periods of 

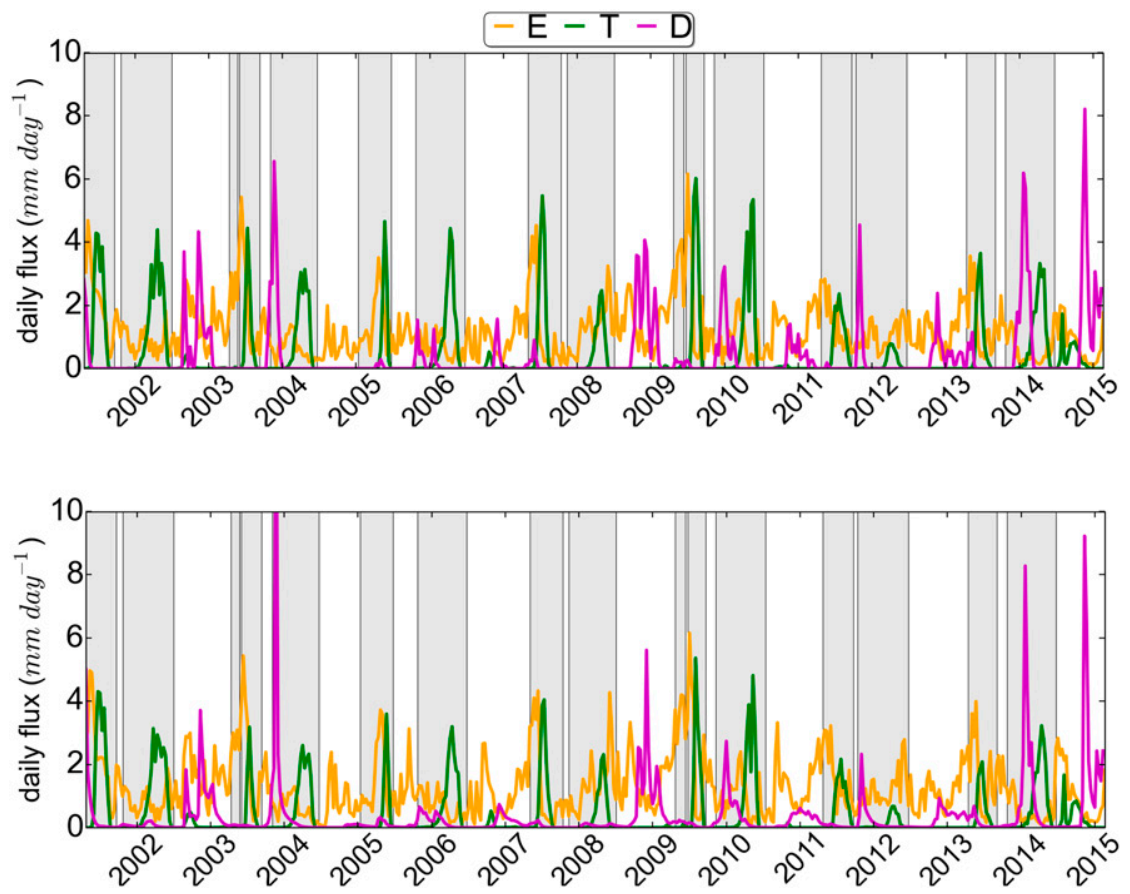

FIG. 6. Time evolution of simulated $E, T$, and $D$ over the 14 -yr crop succession. The fluxes are 10-day average of daily fluxes $\left(\mathrm{mm} \mathrm{day}^{-1}\right.$ ). (top) $\mathrm{FR}_{\mathrm{LOC}}$ experiment and (bottom) $\mathrm{DIF}_{\mathrm{LOC}}$ experiment. Gray and white backgrounds represent crop cycle and intercrop periods, respectively.

time in autumn and winter for a Mediterranean climate. Thus, drainage is triggered over shorter periods of time compared to ET, for which soil evaporation is steadier over the year. While cumulative drainage is lower than cumulative ET over the simulation period, it can locally reach higher values than transpiration (Fig. 6) in response to intense rain events.

\section{2) IMPACT ON SIMULATED ET PERFORMANCES}

When the pedotransfer estimates of the soil parameters are used, the multilayer soil diffusion scheme
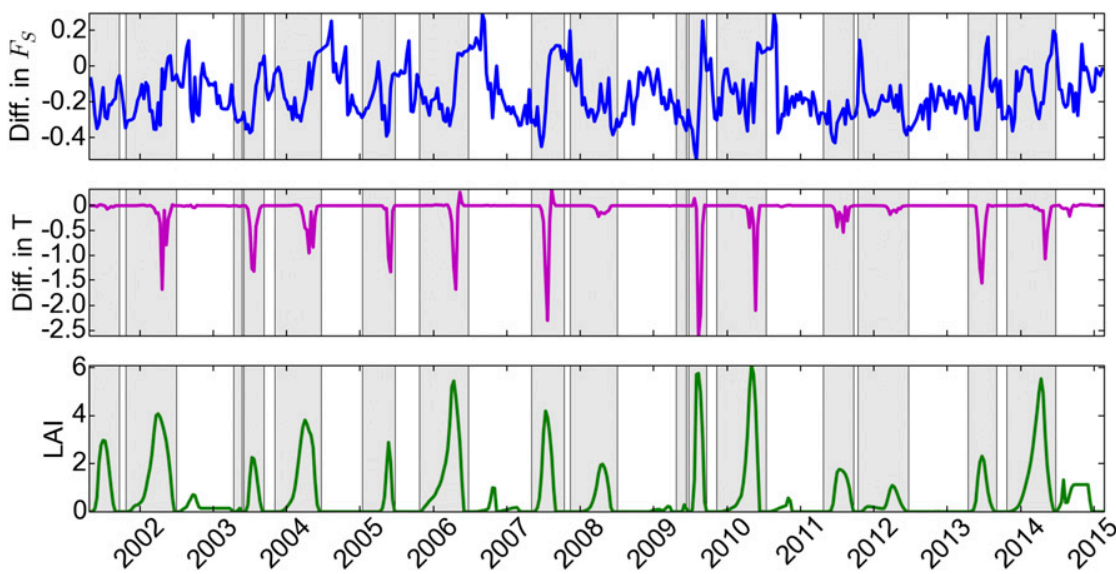

FIG. 7. Time evolution of (top) the differences (Diff.) in $F_{S}$ and (middle) the differences in simulated $T$ between the $\mathrm{DIF}_{\mathrm{LOC}}$ and $\mathrm{FR}_{\mathrm{LOC}}$ experiments over the 14 -yr crop succession. A 10-day average of daily cumulative values is represented for $T\left(\mathrm{~mm} \mathrm{day}^{-1}\right)$ and a 10-day average of daily mean values is used for $F_{s}$. (bottom) The time evolution of measured LAI. Gray and white backgrounds represent crop cycle and intercrop periods, respectively. 
a)

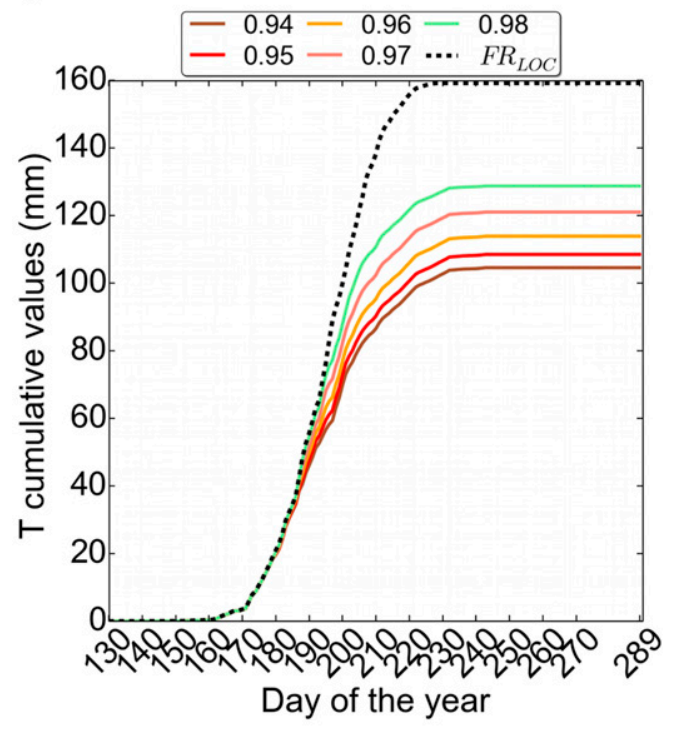

b)

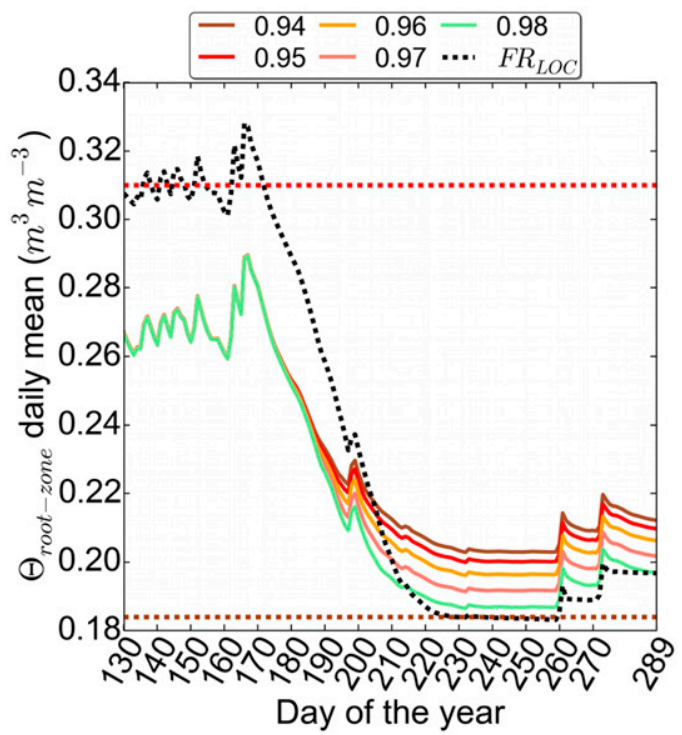

FIG. 8. Sensitivity of (a) transpiration and (b) root-zone soil moisture to the root-extinction coefficient $R_{e}$ over the sorghum cycle in 2007 . The values given in the legend correspond to the five $R_{e}$ values tested in $\mathrm{DIF}_{\mathrm{LOC}}$. The dark and dashed line is the $\mathrm{FR}_{\mathrm{LOC}}$ experiment used for comparison. In (b), the red and brown horizontal dashed lines represent the field capacity (0.31) and the wilting point (0.184) used in these simulations, respectively.

provides the best performance scores and generates very low bias in simulated ET (Table 5) whereas, ET is largely underestimated by force-restore as reported in Garrigues et al. (2015b). The use of the multilayer soil diffusion scheme slightly increases the precision in simulated ET, irrespective of the estimation source of the soil parameters. The gain in performance obtained with the multilayer soil diffusion model is related to more accurate simulations of soil evaporation (Fig. 5), which is the prevailing component of ET over the crop succession. This results in more accurate simulations of soil moisture during wet, bare soil periods.

When locally calibrated soil parameters are used, the performance scores of the force-restore scheme surpass a)

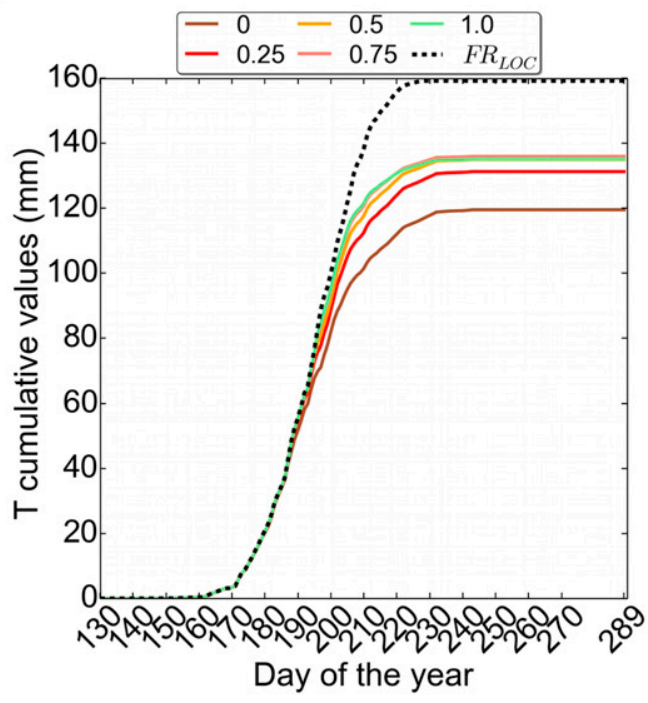

b)

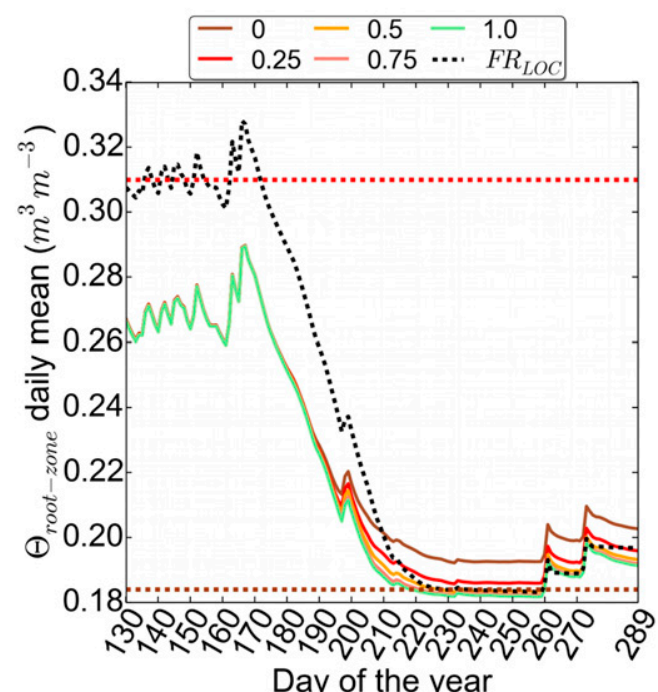

FIG. 9. As in Fig. 8, but for $T$ and $\theta_{\text {root-zone }}$ sensitivity to the proportion of homogeneous root distribution in the root profile $R_{L}$. 
a)

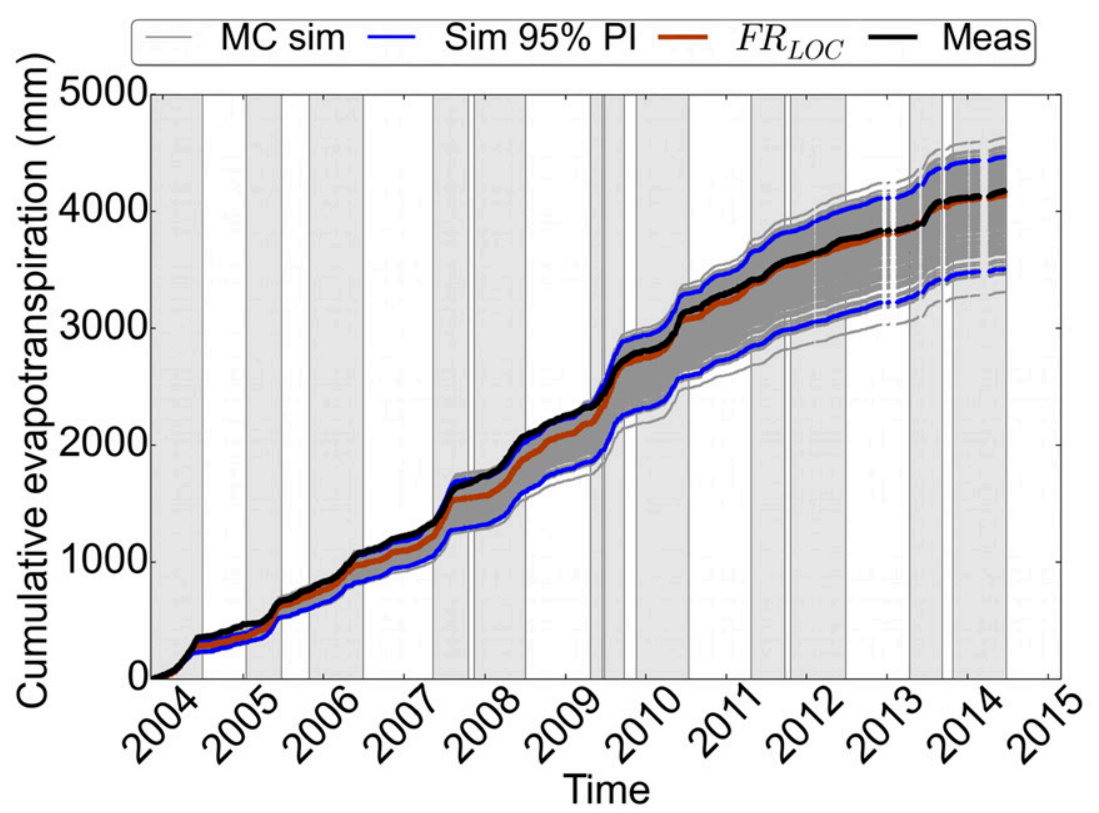

b)

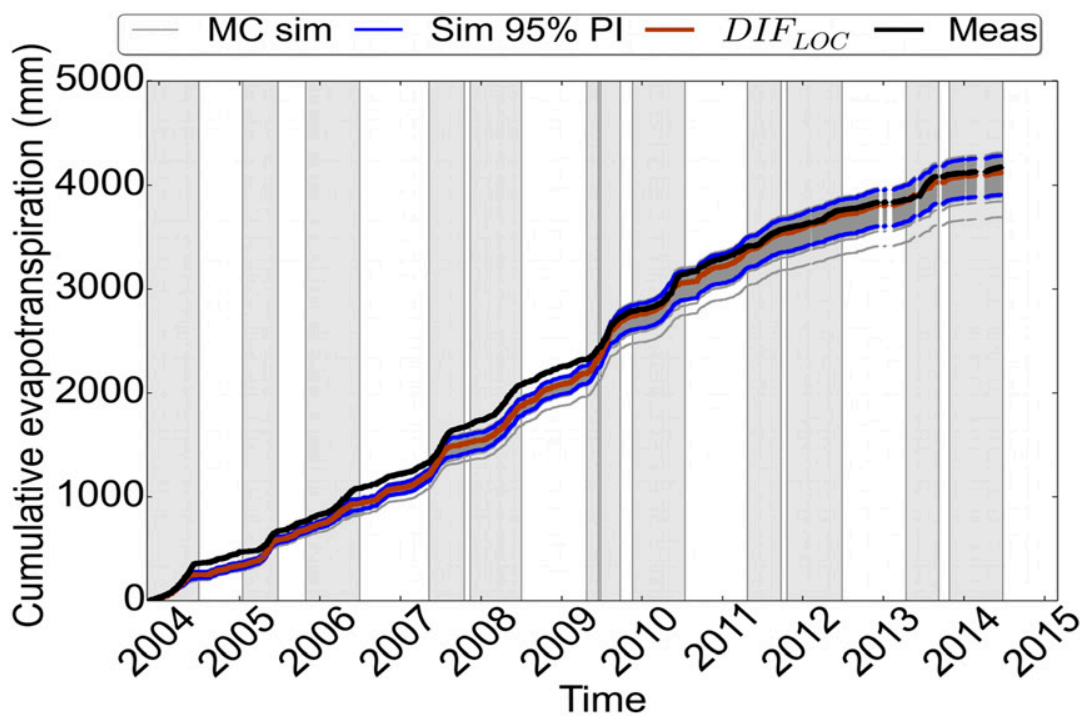

FIG. 10. Propagation of the uncertainties in $Z_{\text {root-zone }}, \theta_{s}, \theta_{\text {fc }}$, and $\theta_{\mathrm{wp}}$ on simulated ET using

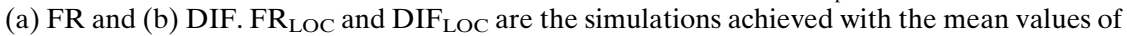
$Z_{\text {root-zone }}, \theta_{s}, \theta_{\text {fc }}$, and $\theta_{\text {wp. }}$. Gray curves represent the 200 simulations generated by Monte Carlo (MC) process. The 95th-percentile interval (PI) of the MC simulations is computed over the empirical distributions of cumulative ET values. Gray and white backgrounds represent crop cycle and intercrop periods, respectively.

those of the multilayer soil diffusion scheme (Table 5). In the force-restore approach, the simulation of water transfers is strongly controlled by a few key soil hydraulic parameters: the soil moisture at saturation, at field capacity, and at the wilting point. Conversely, at the local scale, the multilayer soil diffusion model requires more detailed information on the root profile and the vertical distribution of soil properties, as well as fineenough discretization of the superficial soil to ensure accurate simulation of surface fluxes and soil moisture 
(Blyth and Daamen 1997; de Rosnay et al. 2000; Olioso et al. 2002; Decharme et al. 2011).

\section{3) IMPACT ON SIMULATED DRAINAGE}

Differences in ET are strongly related to differences in drainage in force-restore. When the pedotransfer estimates of the soil parameters are used in force-restore, the drainage is probably overestimated because ET is underestimated, and the simulated soil water content is close to the measurements during most drainage spells.

The differences in drainage dynamics between the force-restore and the multilayer soil diffusion experiments are related to the modeling of water transfers in each scheme (see appendix). Force-restore is a reservoir model where the drainage is triggered each time the soil water content is above field capacity, which explains the staircase and discontinuous temporal evolution of simulated drainage. In force-restore, the drainage is proportional to the difference between the soil water content of the deep reservoir and the soil water content at field capacity. In the multilayer soil diffusion scheme, the drainage is explicitly simulated in each layer using Darcy's law and the gradients of matric potential. It is directly proportional to the hydraulic conductivity. This results in more continuous and probably more realistic temporal evolution of the deep drainage. Despite the differences in dynamics, the amount of drainage simulated with force-restore using the local soil parameters is very similar to that simulated with the multilayer soil diffusion scheme. Independent measurements of drainage would be required to properly assess the skills of both models at simulating the dynamics and the amount of drainage.

\section{b. How does the root water uptake parameterization influence the simulation of water stress and its impacts on ET?}

Garrigues et al. (2015b) showed that the simulation of plant transpiration in the force-restore scheme is mainly controlled by MaxAWC for the plant [Eq. (1)]. One would expect that the larger MaxAWC used in the DIF $_{\text {PTF }}$ experiment, compared to that of the FR $_{\text {PTF }}$ experiment (Table 4), would have generated larger transpiration in DIF $\mathrm{PTF}_{\mathrm{PTF}}$. However, both experiments show few differences in cumulative transpiration (Fig. 3). When the same in situ value of MaxAWC is used in $\mathrm{FR}_{\mathrm{LOC}}$ and $\mathrm{DIF}_{\mathrm{LOC}}$, the cumulative transpiration simulated using the force-restore scheme is larger than the cumulative transpiration simulated using the multilayer soil diffusion scheme (Fig. 3). The use of the in situ value of MaxAWC in the force-restore experiment leads to a substantial reduction of the ET biases, while ET simulated from the multilayer soil diffusion scheme is still underestimated at large LAI (Table 5 and Fig. 4). The transpiration simulated with the multilayer soil diffusion scheme declines too early compared to force-restore, and the root-zone soil moisture does not reach the observed wilting point at the end of the cycle (Fig. 4). Below, we discuss possible sources of uncertainties in the parameterization of the root water uptake that can explain the underestimation of transpiration simulated with the multilayer soil diffusion scheme.

Plant transpiration is highly sensitive to the root distribution profile (Desborough 1997; de Rosnay and Polcher 1998; Canal et al. 2014). In this work, we showed that the soil water stress factor computed in the multilayer soil diffusion scheme using an exponential root profile is frequently smaller (which means larger stress) than the one computed in the force-restore scheme, where a homogeneous root profile is assumed. This explains the smaller transpiration obtained at large LAI with the multilayer soil diffusion scheme compared to the force-restore scheme (Fig. 7). We also showed that increasing the values of the root extinction coefficient (deeper root profile) and the proportion of homogeneous root distribution compared to the standard values used in ISBA delays the occurrence of water stress in better agreement with the observations. Our study suggests that in the absence of detailed root profile characteristics, the use of a near-homogeneous root distribution provides a better simulation of ET than does the use of an exponential profile. While this result holds for a large range of crop and surface conditions taken over the crop succession, it may be influenced by the low heterogeneity of the soil-texture profile of the Avignon site, and it needs to be confirmed for a wider variety of soils, crops, and climates.

Root water uptake is a nonlocal process affected by nonuniform soil water distribution in the root zone, where a plant can increase water uptake in wetter layers to compensate for uptake reductions in drier layers (Braud et al. 2005; Jarvis 2011). As shown in dos Santos et al. (2017), models that do not account for this process tend to underestimate the plant transpiration during dry spells. Additionally, most LSMs do not represent the temporal dynamic of the root front, which is driven by crop phenology and changes in soil structure. The multilayer soil diffusion scheme would permit representing time-varying rooting depth; this would lead to nonconservation of mass issues in force-restore. However, an accurate representation of the complex geometrical and operational functions of the root system and its complex interactions with soil would require threedimensional models (Javaux et al. 2013) that may not be suitable for large-scale LSM applications. 
Other sources of uncertainties are related to the representation of the soil water stress [Eq. (2)]. In most LSMs, the water stress parameterization relies on a linear function of normalized soil water content (Calvet et al. 2004; Best et al. 2011). Verhoef and Egea (2014) showed that using soil matric potential instead of soil moisture provides a more realistic representation of the variability of plants' responses to drought. This offers the potential to implement a detailed plant hydraulic scheme that relates the soil water potential to the leaf potential and takes into account chemical signaling from roots to leaves (Tardieu and Davies 1993; Dewar 2002; Sinclair 2005). Metselaar and de Jong van Lier (2007) and Egea et al. (2011) showed that the plant response to water stress is better modeled by power law functions compared to the linear functions used in Eqs. (2) and (3). Additionally, there is still a debate whether photosynthesis limitations by drought concern stomatal versus nonstomal processes or diffusional versus biochemical components (Zhou et al. 2013). In ISBA-A-gs, soil water stress limitations are exclusively applied to diffusional components (mesophyll conductance and sensitivity of stomatal conductance to air humidity deficit). Egea et al. (2011) showed that while diffusional limitations prevail during mild-to-moderate water stress, biochemical limitations need to be represented during severe water stress.

\section{c. How sensitive are FR and DIF to errors and uncertainties in the soil parameters?}

Garrigues et al. (2015b) highlighted the strong sensitivity of force-restore simulations of soil evaporation to the values of the soil moisture at field capacity and the soil moisture at saturation. In this work, we report a strong sensitivity of the simulation of drainage with force-restore to the soil parameters. We showed that the simulations of soil evaporation and drainage with the multilayer soil diffusion scheme are less sensitive to the values of the soil parameters (Fig. 5). Changing the value of the field capacity in force-restore modifies the dynamics of the soil moisture in winter, which tends to be restored to field capacity via drainage. Conversely, in the multilayer soil diffusion scheme, the simulation of water transfers is driven by the hydraulic conductivity and the vertical gradients of matric potential (Decharme et al. 2011). In force-restore, the dynamic of the superficial soil moisture is controlled by the value of soil moisture at saturation used to parameterize the hydraulic diffusivity of the superficial layer (Mahfouf and Noilhan 1991; Garrigues et al. 2015b), while in the multilayer scheme, superficial soil moisture is simulated using Darcy's law. This can generate large differences in the resulting soil evaporation. d. What are the benefits and the challenges in using DIF versus FR for large-scale applications?

\section{1) LOW SENSITIVITY TO SPATIOTEMPORAL UNCERTAINTIES IN THE SOIL PARAMETERS}

We showed that spatiotemporal uncertainties in the soil parameters generate smaller uncertainties in ET when ET is simulated with the multilayer soil diffusion scheme compared to force-restore (Fig. 10). The multilayer soil diffusion scheme should be more robust to errors in soil properties for regional- to global-scale applications, particularly for the simulation of soil evaporation. Conversely, the performances of forcerestore strongly depend on the calibration of a few parameters that may generate larger uncertainties when it is applied at large scale.

\section{2) BETTER REPRESENTATION OF PHYSICAL PROCESSES}

We showed that the multilayer soil diffusion scheme provides more realistic simulations of soil evaporation and drainage. It also allows representations of the following:

- Soil vertical heterogeneity: Olioso et al. (2002) and Decharme et al. (2011) have shown substantial improvement in simulated soil moisture and fluxes compared to force-restore, when the vertical distribution of soil hydraulic properties is represented in the multilayer scheme. It was not possible to test it in this work because of insufficient observations on the soilproperty vertical profile.

- Capillary rise from a shallow water table: The approach consists of using the water-table depth as the lower-boundary condition for the soil moisture diffusive equation. Vergnes et al. (2014) showed that capillary rise from a shallow water table can increase the mean annual ET simulated over the aquifer by $1 \%-3 \%$; locally, the increase can reach $30 \%-50 \%$.

\section{3) Challenges For the SPATIAL INTEGRATION OF LSMS}

This study pointed out the large impact of the soil water transfer parameterization on the simulation of ET for a crop succession. Garrigues et al. (2015a) showed that the soil parameters have a larger influence on the simulation of ET than do climate and vegetation drivers.

The parameterization of the water transfer schemes and the propagation of the associated uncertainties on simulated ET represent important challenges for the spatial integration of LSMs at large scale. For both the force-restore and the multilayer soil diffusion schemes, 
the parameterization of MaxAWC is the main source of uncertainty for the simulation of the plant transpiration when the soil dries down. For the multilayer soil diffusion scheme, the simulation of the soil water stress also requires proper parameterization of the root distribution profile, which may be an additional source of uncertainty for large-scale applications. Further works are required to refine the parameterization of the root profile for a range of crop, soil, and climate conditions.

While our results were demonstrated using the ISBA model, they are generic enough to be applicable to other land surface models. Our results contribute to the GEWEX Soil Parameter Model Intercomparison Project (SP-MIP), which is currently conducting multimodel experiments to relate the spread between LSMs to differences in soil water transfer parameterization.

Future works should target 1) the improvement of key physical parameterizations as identified above (particularly the root water uptake model and water stress model), 2) a stochastic representation of uncertainties in both soil parameters and pedotransfer functions using ensemble predictions, and 3) data assimilation approaches by capitalizing on the increasing number of Earth observation datasets on vegetation dynamic and soil moisture.

\section{Summary}

In this study, we compared the performances of two water transfer schemes at simulating the evapotranspiration dynamics over a 14 -yr Mediterranean crop succession: 1) a three-layer bulk reservoir model that relies on the force-restore approach and 2) a multilayer soil diffusion scheme that explicitly simulates water transfers using mass-diffusive equations and a root distribution profile. Simulations were performed using the SURFEX/ISBA-A-gs model. They were assessed at the field scale over a 14-yr Mediterranean crop succession located in Avignon, France. This site provides 14 years of continuous measurements of soil moisture and surface fluxes, providing a unique opportunity to evaluate land surface models for a large range of soil, crop, and atmospheric states. The intent of this work is to explicitly represent crop rotation in the simulations. The simulations of evapotranspiration, soil evaporation, transpiration, drainage, and soil moisture from both water transfer schemes were compared when they were driven by the standard values of the soil parameters estimated from the ISBA pedotransfer functions versus the in situ values of the soil parameters.

The main outcomes of this work are as follows:

- When the pedotransfer estimates of the soil parameters are used, the multilayer soil diffusion scheme provides the best performance scores. This is related to more accurate simulations of soil evaporation, which is the prevailing component of evapotranspiration over Mediterranean crop successions. When in situ soil parameters are used, the performance of force-restore surpasses that of the multilayer soil diffusion scheme. The use of the proper maximum available water content for the plant in force-restore substantially reduces the bias in evapotranspiration and soil moisture over the crop cycle, as reported in Garrigues et al. (2015b). However, the use of the proper maximum available water content for the plant slightly impacts the ET simulations achieved with the multilayer soil diffusion scheme, where soil water stress is simulated too early and transpiration is underestimated over the crop cycle.

- The simulation of transpiration using the multilayer soil diffusion scheme is sensitive to the parameterization of the root distribution profile. Increasing the values of the root extinction coefficient of the exponential root profile model and the proportion of homogeneous root distribution in the profile compared to the standard values used in ISBA improves the simulation of the timing of soil water stress.

- For the simulation of soil evaporation, the multilayer soil diffusion scheme is less sensitive to errors in the soil parameters compared to force-restore. In forcerestore, the simulation of soil water transfers is strongly controlled by the soil moisture at field capacity and the soil moisture at saturation. Conversely, in the multilayer soil diffusion scheme, soil water transfers are explicitly simulated using gradients of matric potential and Darcy's law, which generates more accurate simulations of soil evaporation and soil moisture over bare soil and more realistic simulations of the deep-drainage dynamic.

- We showed through Monte Carlo analysis that the spatiotemporal uncertainties in the soil parameters generate smaller uncertainties in evapotranspiration when it is simulated with the multilayer soil diffusion scheme compared to force-restore.

This work showed that the soil water transfer parameterization has a large impact on the simulation of evapotranspiration and thus represents an important challenge for the spatial integration of LSMs at large scale (from regional to global scale). The simulation of soil evaporation from the multilayer soil diffusion scheme should be more robust to the spatial uncertainties in the soil properties compared to forcerestore, which strongly depends on the calibration of the soil parameters. This represents a clear advantage for using the multilayer soil diffusion scheme for large-scale 
applications. The multilayer soil diffusion scheme is a more realistic model and can account for additional hydrological aspects that can strongly influence the simulation of evapotranspiration such as the vertical heterogeneity of the soil hydraulic properties, upward capillary rise from the water table, and coupling between the soil and the plant hydraulic properties. Future work is needed to improve the description of the spatial variability of the soil properties, particularly those involved in the maximum available water content for the plant and the root profile, which are key drivers of the impact of soil water stress on evapotranspiration. Finally, methodologies need to be developed to characterize the spatiotemporal uncertainties in the soil parameters and propagate them on simulated evapotranspiration using ensemble predictions.

Acknowledgments. This work was made possible thanks to the financial support of Centre National d'Etudes Spatiales (CNES) through the TOSCA program (PITEAS and EVASPA.v3.0 projects). Part of the work was conducted at the Centre for Ecology and Hydrology (CEH, Wallingford, United Kingdom) and at University of Reading, United Kingdom (Department of Geography and Environmental Science). Sébastien Garrigues has received the support of the EU in the framework of the Marie-Curie FP7 COFUND People Programme, through the award of an AgreenSkills+ fellowship (under Grant Agreement FP7-609398).

\section{APPENDIX}

\section{Water Transfer Model Equations}

\section{a. Force-restore model with three reservoirs}

\section{1) Governing EQuATIONS}

Surface runoff and frozen soil are neglected for the Avignon site. The continuity equations of the forcerestore scheme with three reservoirs are given by

$$
\begin{aligned}
\frac{\partial \theta_{\text {surf }}}{\partial t} & =\frac{C_{1}}{\rho_{w} Z_{\text {surf }}}(P-E)-\frac{C_{2}}{\tau}\left(\theta_{\text {surf }}-\theta_{\text {eq }}\right), \\
\frac{\partial \theta_{\text {root-zone }}}{\partial t} & =\frac{1}{\rho_{w} Z_{\text {root-zone }}}(P-E-T)-K_{\text {root-zone }}-D_{\text {root-zone }},
\end{aligned}
$$

and

$$
\frac{\partial \theta_{\text {deep }}}{\partial t}=\frac{Z_{\text {root-zone }}}{Z_{\text {deep }}-Z_{\text {root-zone }}}\left(K_{\text {root-zone }}+D_{\text {root-zone }}\right)-K_{\text {deep }} .
$$

Parameter $\rho_{w}$ is the liquid water density, $P$ is the flux of water reaching the surface, $E$ is the soil evaporation, $T$ is the plant transpiration, and $\tau$ is the restore constant of one day. The depths of the superficial layer $(1 \mathrm{~cm})$, root zone, and deep reservoir are $Z_{\text {surf }}, Z_{\text {root-zone, and }} Z_{\text {deep }}$, respectively, and $\theta_{\text {surf }}, \theta_{\text {root-zone, }}$, and $\theta_{\text {deep }}$ are the volumetric soil moisture of the superficial layer, root zone, and deep reservoir, respectively. The first term on the right-hand side of Eq. (A1) is the forcing term where the coefficient $C_{1}$ is driving the moisture exchange between the surface and the atmosphere. The second term on the right-hand side of Eq. (A1) is the restore term, which represents the vertical water diffusion between the root zone and the superficial layer. It is ruled by the diffusion coefficient $C_{2}$, which quantifies the rate at which the soil moisture profile between the superficial layer and the root zone is restored to the soil moisture at equilibrium $\theta_{\text {eq }}$ (water content at the balance between the gravity and the capillary forces). In Eqs. (A2) and (A3), $D_{\text {root- }}$ zone is the vertical water diffusion term between the root zone and the deep reservoir. It is given by

$$
D_{\text {root-zone }}=\frac{C_{4}}{\tau}\left(\theta_{\text {root-zone }}-\theta_{\text {deep }}\right),
$$

where $C_{4}$ represents the rate at which the soil moisture profile between the root zone and the deep reservoir is restored to the equilibrium $\left(\theta_{\text {root-zone }}=\theta_{\text {deep }}\right)$. Parameters $K_{\text {root-zone }}$ and $K_{\text {deep }}$ are the drainage terms that are described below. Detailed equations of the force-restore coefficients for the three-reservoir scheme can be found in Mahfouf and Noilhan (1996) and Boone et al. (1999).

\section{2) Drainage}

The drainage from the root zone to the deep layer is

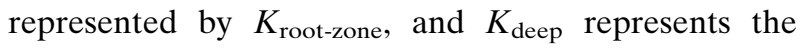
drainage out of the deep layer. In force-restore, drainage is computed as a restore term starting from saturation toward field capacity:

$$
K_{\text {root-zone }}=\frac{C_{3}}{\tau Z_{\text {root-zone }}} \max \left[\theta_{r, \text { root-zone }},\left(\theta_{\text {root-zone }}-\theta_{\text {fc }}\right)\right]
$$

and

$$
K_{\text {deep }}=\frac{C_{3}}{\tau\left(Z_{\text {deep }}-Z_{\text {root-zone }}\right)} \max \left[\theta_{r \text {,deep }},\left(\theta_{\text {deep }}-\theta_{\text {fc }}\right)\right] .
$$

In Eqs. (A5) and (A6), $\theta_{\mathrm{fc}}$ is the soil moisture at field capacity, and $\theta_{r \text {,root-zone }}$ and $\theta_{r}$,deep represent the soil water contents related to residual drainage terms in the root zone and deep layer, respectively. The residual 
drainage is triggered when the soil moisture is lower than field capacity to account for soil moisture heterogeneity within the grid cell. Parameter $C_{3}$ represents the drainage rate at which the soil water content is restored to the field capacity; it has been analytically derived from a diffusive model and then related to the clay fraction $f_{\text {clay }}$ by Noilhan and Mahfouf (1996):

$$
C_{3}=5.327 f_{\text {clay }}^{-1.043} \text {. }
$$

The total deep drainage $D_{\mathrm{FR}}$ predicted by the ISBA force-restore scheme is given by

$D_{\mathrm{FR}}=\rho_{w}\left(Z_{\text {deep }}-Z_{\text {root-zone }}\right) K_{\text {deep }}+R_{\text {root-zone,sat }}+R_{\text {deep,sat }}$,

where $R_{\text {root-zone,sat }}$ and $R_{\text {deep,sat }}$ are the subsurface runoffs that are simulated when the soil water content of the root zone and deep layer, respectively, are above the soil water content at saturation $\theta_{\text {sat }}$. These terms are given by

$R_{\text {root-zone }}=\frac{\rho_{w} Z_{\text {root-zone }}}{\Delta t} \max \left(0, \theta_{\text {root-zone }}-\theta_{\text {sat }}\right) \quad$ and

$$
R_{\text {deep,sat }}=\frac{\rho_{w}\left(Z_{\text {deep }}-Z_{\text {root-zone }}\right)}{\Delta t} \max \left(0, \theta_{\text {deep }}-\theta_{\text {sat }}\right),
$$

where $\Delta t$ is the model time step.

\section{b. Multilayer soil diffusion scheme}

\section{1) Governing equations}

The vertical soil water flux $F$ simulated by the multilayer soil diffusion scheme is given by

$$
F=-\eta \frac{\partial \psi}{\partial z}-\zeta
$$

with

$$
\eta=\varphi\left(k+\frac{D_{v, \psi}}{\rho_{w}}\right)
$$

and

$$
\zeta=k+K_{d} .
$$

Parameter $\eta\left(\mathrm{m}^{2} \mathrm{~s}^{-1}\right)$ is the effective diffusion coefficient, $\psi(\mathrm{m})$ is the soil matric potential, $k\left(\mathrm{~m} \mathrm{~s}^{-1}\right)$ is the hydraulic conductivity, and $K_{d}\left(\mathrm{~m} \mathrm{~s}^{-1}\right)$ is the linear background drainage term to ensure a minimum water flow out of the soil column. Parameter $D_{v, \psi}\left(\mathrm{kg} \mathrm{m}^{-2} \mathrm{~s}^{-1}\right)$ is the isothermal vapor conductivity that is a function of texture, water content, and temperature following Braud et al. (1993). Parameter $\varphi$ is a nondimensional coefficient which represents the ice impedance and acts to limit vertical diffusion (reduction of the hydraulic conductivity) in the presence of a freezing front; $\varphi$ is calculated following Johnsson and Lundin (1991).

In Eq. (A11), $-\eta(\partial \psi / \partial z)$ represents the diffusion, which is generally oriented upward, while $\zeta$ represents the total drainage, which is oriented downward.

The governing equations of the multilayer soil diffusion scheme are the mixed form of the Richards equation derived from Eq. (A11):

$\frac{\partial \theta_{1}}{\partial t}=\frac{1}{\Delta Z_{1}}\left[-\overline{k_{1}}\left(\frac{\psi_{1}-\psi_{2}}{\Delta \overline{Z_{1}}}+1\right)-\overline{v_{1}} \frac{\psi_{1}-\psi_{2}}{\Delta \overline{Z_{1}}}+\frac{S_{1}}{\rho_{w}}\right]$ and

$$
\begin{aligned}
\frac{\partial \theta_{i}}{\partial t} & =\frac{1}{\Delta Z_{i}}\left(F_{i-1}-F_{i}+\frac{S_{i}}{\rho_{w}}\right), \text { with } \\
F_{i} & =\bar{k}_{i}\left(\frac{\psi_{i}-\psi_{i+1}}{\Delta \bar{Z}_{i}}+1\right)+\bar{v}_{i}\left(\frac{\psi_{i}-\psi_{i+1}}{\Delta \bar{Z}_{i}}\right) .
\end{aligned}
$$

Equation (A14) describes the evolution of the superficial soil moisture $\theta_{1}$. Equation (A15) provides the evolution of the soil water content $\theta_{i}$ for the rest of the soil layers. In these equations, $\Delta Z_{i}(\mathrm{~m})$ is the thickness of the $i$ layer, $\Delta \overline{Z_{i}}(\mathrm{~m})$ is the thickness between two consecutive layer nodes (midpoint), $\psi_{i}$ is the matric potential (m) of the $i$ th layer, $\overline{v_{i}}\left(\mathrm{~m} \mathrm{~s}^{-1}\right)$ is the geometric mean of the isothermal vapor conductivity over two consecutive soil layer nodes, $\overrightarrow{k_{i}}\left(\mathrm{~m} \mathrm{~s}^{-1}\right)$ is the geometric mean of the hydraulic conductivity over two consecutive soil layer nodes, and $S_{i}$ is the soil water source/sink term related to the land surface infiltration and evapotranspiration processes.

\section{2) ROOT-DENSITY PROFILE}

The root-density profile used to partition the plant water uptake in the root zone and to compute the water stress function is a linear combination of a homogeneous profile [first term of the right-hand side of Eq. (A16)] and the Jackson et al. (1996) exponential profile [second term of the right-hand side of Eq. (A16)]

$$
Y_{\text {ISBA }}\left(Z_{i}\right)=R_{L} \frac{Z_{i}}{Z_{\text {root-zone }}}+\left(1-R_{L}\right) Y_{\text {Jackson }}\left(Z_{i}\right),
$$

where

$$
Y_{\text {Jackson }}\left(Z_{i}\right)=\frac{\left(1-R_{e}^{100 Z_{i}}\right)}{\left(1-R_{e}^{100 Z_{\text {root-zone }}}\right)} .
$$


a)

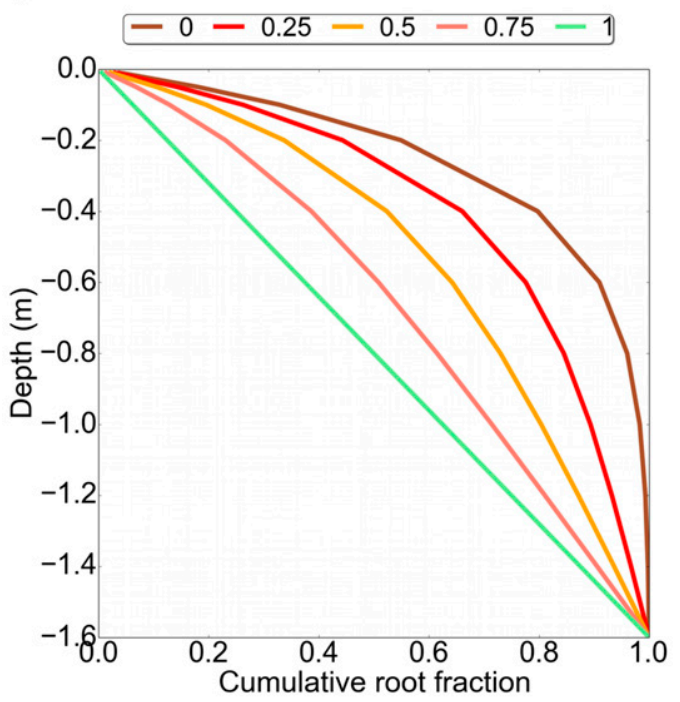

b)

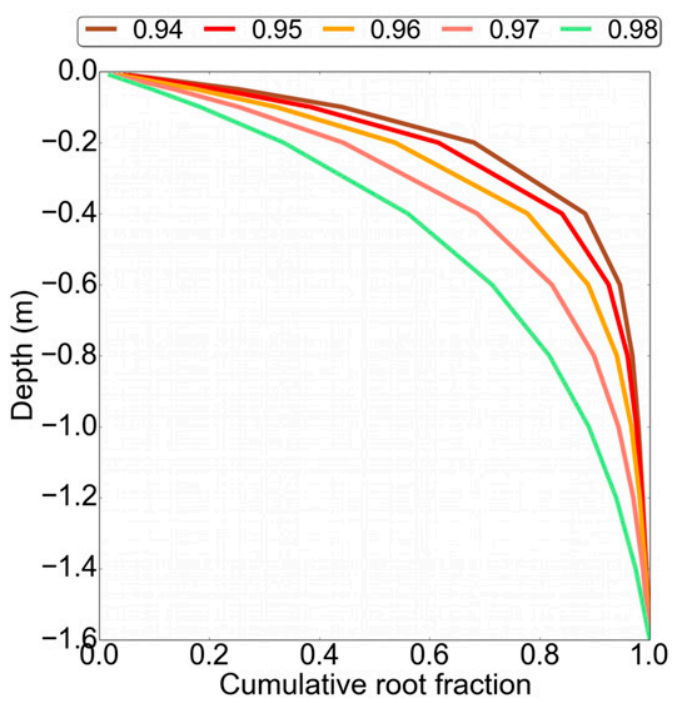

FIGURE A1. Root fraction profile as a function of (a) $R_{L}$ and (b) $R_{e}$. The legends of (a) and (b) indicate the values of $R_{L}$ and $R_{e}$, respectively. In (a), $R_{e}=0.96$ and in (b), $R_{L}=0.05$.

Variable $Y_{\text {ISBA }}\left(Z_{i}\right)$ is the cumulative root density from the surface to the depth $Z_{i}$ computed by ISBA. Parameter $Z_{\text {root-zone }}$ is the maximum rooting depth. Parameter $R_{L}$ is the proportion of homogeneous distribution in the root profile. In the standard implementation of the model, $R_{L}$ is set to $5 \%$ for all vegetation types. In Eq. (A17), $Y_{\text {Jackson }}\left(Z_{i}\right)$ is the cumulative root density from the surface to the depth $Z_{i}$ computed by the Jackson model, and $R_{e}$ is the root extinction coefficient equal to 0.961 and 0.972 for $\mathrm{C} 3$ and C4 crops, respectively. Low values of $R_{e}$ indicate a higher density of roots in the top layer, while larger values of $R_{e}$ generate a deeper root profile. Figure A1 displays the vertical distributions of root fraction for the values of $R_{e}$ and $R_{L}$ investigated in this paper.

\section{3) DeEp DRAinage}

The total deep drainage $D_{\mathrm{DIF}}$ out of the bottom of the soil column computed by the ISBA multilayer soil diffusion scheme is equal to the flux out of the bottom of the last layer. It is equal to the hydraulic conductivity of the last layer $k_{N}$ plus the subsurface runoff $R_{N, \text { sat }}$ when the soil water content of the last layer $\theta_{N}$ is above saturation $\theta_{N, \text { sat }}$ :

$$
\begin{aligned}
D_{\mathrm{DIF}} & =k_{N}+R_{N, \text { sat }} \text { and } \\
R_{N, \text { sat }} & =\frac{\rho_{w}\left(\Delta Z_{N}\right)}{\Delta t} \max \left(0, \theta_{N}-\theta_{N, \text { sat }}\right),
\end{aligned}
$$

where $\Delta Z_{N}$ is the thickness of the last layer, and $\Delta t$ is the model time step.

\section{REFERENCES}

Best, M. J., and Coauthors, 2011: The Joint UK Land Environment Simulator (JULES), Model description - Part 1: Energy and water fluxes. Geosci. Model Dev., 4, 677-699, https://doi.org/ 10.5194/gmd-4-677-2011.

Béziat, P., E. Ceschia, and G. Dedieu, 2009: Carbon balance of a three crop succession over two cropland sites in south west France. Agric. For. Meteor., 149, 1628-1645, https://doi.org/ 10.1016/j.agrformet.2009.05.004.

Bhumralkar, C. M., 1975: Numerical experiments on the computation of ground surface temperature in an atmospheric general circulation model. J. Appl. Meteor., 14, 1246-1258, https:// doi.org/10.1175/1520-0450(1975)014<1246:NEOTCO > 2.0.CO;2.

Blackadar, A. K., 1976: Modeling the nocturnal boundary layer. Preprints, Third Symp. on Atmospheric Turbulence, Diffusion and Air Quality, Raleigh, NC, Amer. Meteor. Soc., 46-49.

Blyth, E. M., and C. C. Daamen, 1997: The accuracy of simple soil water models in climate forecasting. Hydrol. Earth Syst. Sci., 1, 241-248, https://doi.org/10.5194/hess-1-241-1997.

Boone, A., J.-C. Calvet, and J. Noilhan, 1999: Inclusion of a third soil layer in a land surface scheme using the force-restore method. J. Appl. Meteor., 38, 1611-1630, https://doi.org/ 10.1175/1520-0450(1999)038<1611:IOATSL > 2.0.CO;2.

Braud, I., J. Noilhan, P. Bessemoulin, P. Mascart, R. Haverkamp, and M. Vauclin, 1993: Bare ground surface heat and water exchanges under dry conditions: Observation and parameterization. Bound.-Layer Meteor., 66, 173-200, https://doi.org/ 10.1007/BF00705465.

_- N. Varado, and A. Olioso, 2005: Comparison of root water uptake modules using either the surface energy balance or potential transpiration. J. Hydrol., 301, 267-286, https:// doi.org/10.1016/j.jhydrol.2004.06.033.

Brooks, R. H., and A. T. Corey, 1966: Properties of porous media affecting fluid flow. J. Irrig. Drain. Div., Amer. Soc. Civ. Eng., 92, 61-90.

Calvet, J.-C., J. Noilhan, J.-L. Roujean, P. Bessemoulin, M. Cabelguenne, A. Olioso, and J.-P. Wigneron, 1998: An 
interactive vegetation SVAT model tested against data from six contrasting sites. Agric. For. Meteor., 92, 73-95, https://doi.org/ 10.1016/S0168-1923(98)00091-4.

— , V. Rivalland, C. Picon-Cochard, and J.-M. Guehl, 2004: Modelling forest transpiration and $\mathrm{CO}_{2}$ fluxes-Response to soil moisture stress. Agric. For. Meteor., 124, 143-156, https:// doi.org/10.1016/j.agrformet.2004.01.007.

, S. Lafont, E. Cloppet, F. Souverain, V. Badeau, and C. Le Bas, 2012: Use of agricultural statistics to verify the interannual variability in land surface models: A case study over France with ISBA-A-gs. Geosci. Model Dev., 5, 37-54, https://doi.org/10.5194/gmd-5-37-2012.

Canal, N., J.-C. Calvet, B. Decharme, D. Carrer, S. Lafont, and G. Pigeon, 2014: Evaluation of root water uptake in the ISBAA-gs land surface model using agricultural yield statistics over France. Hydrol. Earth Syst. Sci., 18, 4979-4999, https://doi.org/ 10.5194/hess-18-4979-2014.

Clapp, R., and G. Hornberger, 1978: Empirical equations for some soil hydraulic properties. Water Resour. Res., 14, 601-604, https://doi.org/10.1029/WR014i004p00601.

Dai, Y., and Coauthors, 2003: The Common Land Model. Bull. Amer. Meteor. Soc., 84, 1013-1023, https://doi.org/10.1175/ BAMS-84-8-1013.

Deardorff, J. W., 1977: A parameterization of ground surface moisture content for use in atmospheric prediction models. J. Appl. Meteor., 16, 1182-1185, https://doi.org/10.1175/15200450(1977)016<1182:APOGSM > 2.0.CO;2.

Decharme, B., A. Boone, C. Delire, and J. Noilhan, 2011: Local evaluation of the Interaction between Soil Biosphere Atmosphere soil multilayer diffusion scheme using four pedotransfer functions. J. Geophys. Res., 116, D20126, https:// doi.org/10.1029/2011JD016002.

_- E. Martin, and S. Faroux, 2013: Reconciling soil thermal and hydrological lower boundary conditions in land surface models. J. Geophys. Res. Atmos., 118, 7819-7834, https:// doi.org/10.1002/jgrd.50631.

— - E. Brun, A. Boone, C. Delire, P. Le Moigne, and S. Morin, 2016: Impacts of snow and organic soils parameterization on northern Eurasian soil temperature profiles simulated by the ISBA land surface model. Cryosphere, 10, 853-877, https:// doi.org/10.5194/tc-10-853-2016.

de Rosnay, P., M. Bruen, and J. Polcher, 2000: Sensitivity of surface fluxes to the number of layers in the soil model used in GCMs. Geophys. Res. Lett., 27, 3329-3332, https://doi.org/10.1029/2000GL011574.

— tercomparison experiment coupled to the Community Microwave Emission Model: ALMIP-MEM. J. Geophys. Res., 114, D05108, https://doi.org/10.1029/2008JD010724.

Desborough, C. E., 1997: The impact of root weighting on the response of transpiration to moisture stress in land surface schemes. Mon. Wea. Rev., 125, 1920-1930, https://doi.org/ 10.1175/1520-0493(1997)125<1920:TIORWO > 2.0.CO;2.

Dewar, R. C., 2002: The Ball-Berry-Leuning and Tardieu-Davies stomatal models: Synthesis and extension within a spatially aggregated picture of guard cell function. Plant Cell Environ., 25, 1383-1398, https://doi.org/10.1046/j.1365-3040.2002.00909.x.

dos Santos, M. A., Q. de Jong van Lier, J. C. van Dam, and A. H. Freire Bezerra, 2017: Benchmarking test of empirical root water uptake models. Hydrol. Earth Syst. Sci., 21, 473-493, https://doi.org/10.5194/hess-21-473-2017.

Egea, G., A. Verhoef, and P. L. Vidale, 2011: Towards an improved and more flexible representation of water stress in coupled photosynthesis-stomatal conductance models. Agric. For. Meteor., 151, 1370-1384, https://doi.org/10.1016/j.agrformet.2011.05.019.
Faroux, S., A. T. Kaptué Tchuenté, J.-L. Roujean, V. Masson, E. Martin, and P. Le Moigne, 2013: ECOCLIMAP-II/Europe: A twofold database of ecosystems and surface parameters at $1 \mathrm{~km}$ resolution based on satellite information for use in land surface, meteorological and climate models. Geosci. Model Dev., 6, 563-582, https://doi.org/10.5194/gmd-6-563-2013.

Foken, T., M. Göckede, M. Mauder, L. Mahrt, B. Amiro, and W. Munger, 2004: Post-field data quality control. Handbook of Micrometeorology: A Guide for Surface Flux Measurement and Analysis, X. Lee, W. Massman, and B. E. Law, Eds., Atmospheric and Oceanographic Sciences Library Series, Vol. 29, Springer, 181-208.

Garrigues, S., A. Olioso, D. Carrer, B. Decharme, J.-C. Calvet, E. Martin, S. Moulin, and O. Marloie, 2015a: Impact of climate, vegetation, soil and crop management variables on multi-year ISBA-A-gs simulations of evapotranspiration over a Mediterranean crop site. Geosci. Model Dev., 8, 30333053, https://doi.org/10.5194/gmd-8-3033-2015.

_ lations of evapotranspiration over a 12-year crop succession: Impact of soil hydraulic and vegetation properties. Hydrol. Earth Syst. Sci., 19, 3109-3131, https://doi.org/10.5194/hess-19-3109-2015.

Gibelin, A.-L., J.-C. Calvet, J.-L. Roujean, L. Jarlan, and S. O. Los, 2006: Ability of the land surface model ISBA-A-gs to simulate leaf area index at the global scale: Comparison with satellites products. J. Geophys. Res., 111, D18102, https://doi.org/ 10.1029/2005JD006691.

Goudriaan, J., H. H. van Laar, H. van Keulen, and W. Louwerse, 1985: Photosynthesis, $\mathrm{CO}_{2}$ and plant production. Wheat Growth and Modeling, W. Day and R. K. Atkin, Eds., NATO ASI Series A: Life Sciences, Vol. 86, Plenum Press, 107-122.

Habets, F., A. Boone, and J. Noilhan, 2003: Simulation of a Scandinavian basin using the diffusion transfer version of ISBA. Global Planet. Change, 38, 137-149, https://doi.org/10.1016/ S0921-8181(03)00016-X.

_ - and Coauthors, 2008: The SAFRAN-ISBA-MODCOU hydrometeorological model applied over France. J. Geophys. Res., 113, D06113, https://doi.org/10.1029/2007JD008548.

Jackson, R. B., J. Canadell, J. R. Ehleringer, H. A. Mooney, O. E. Sala, and E. D. Schulze, 1996: A global analysis of root distributions for terrestrial biomes. Oecologia, 108, 389-411, https://doi.org/10.1007/BF00333714.

Jacobs, C. M. J., B. M. M. van den Hurk, and H. A. R. de Bruin, 1996: Stomatal behaviour and photosynthetic rate of unstressed grapevines in semi-arid conditions. Agric. For. Meteor., 80, 111134, https://doi.org/10.1016/0168-1923(95)02295-3.

Jarvis, N. J., 2011: Simple physics-based models of compensatory plant water uptake: Concepts and eco-hydrological consequences. Hydrol. Earth Syst. Sci., 15, 3431-3446, https:// doi.org/10.5194/hess-15-3431-2011.

Javaux, M., V. Couvreur, J. Vanderborght, and H. Vereecken, 2013: Root water uptake: From three-dimensional biophysical processes to macroscopic modeling approaches. Vadose Zone J., 12, https://doi.org/10.2136/vzj2013.02.0042.

Johnsson, H., and L.-C. Lundin, 1991: Surface runoff and soil water percolation as affected by snow and soil frost. J. Hydrol., 122, 141-159, https://doi.org/10.1016/0022-1694(91)90177-J.

Kutilek, M., and D. R. Nielsen, 1994: Soil Hydrology. Catena Verlag, $370 \mathrm{pp}$.

Mahfouf, J.-F., and J. Noilhan, 1991: Comparative study of various formulations of evaporations from bare soil using in situ data. J. Appl. Meteor., 30, 1354-1365, https://doi.org/10.1175/ 1520-0450(1991)030<1354:CSOVFO >2.0.CO;2. 
— , and — 1996: Inclusion of gravitational drainage in a land surface scheme based on the force-restore method. J. Appl. Meteor., 35, 987-992, https://doi.org/10.1175/15200450(1996)035<0987:IOGDIA > 2.0.CO;2.

Manzi, A. O., and S. Planton, 1994: Implementation of the ISBA parameterization scheme for land surface processes in a GCM: An annual cycle experiment. J. Hydrol., 155, 353-389, https:// doi.org/10.1016/0022-1694(94)90178-3.

Masson, V., and Coauthors, 2013: The SURFEXv7.2 land and ocean surface platform for coupled or offline simulation of earth surface variables and fluxes. Geosci. Model Dev., 6, 929960, https://doi.org/10.5194/gmd-6-929-2013.

Mauder, M., M. Cuntz, C. Drüe, A. Graf, C. Rebmann, H. P. Schmid, M. Schmidt, and R. Steinbrecher, 2013: A strategy for quality and uncertainty assessment of long-term eddycovariance measurements. Agric. For. Meteor., 169, 122-135, https://doi.org/10.1016/j.agrformet.2012.09.006.

Metselaar, K., and Q. de Jong van Lier, 2007: The shape of the transpiration reduction function under plant water stress. Vadose Zone J., 6, 124-139, https://doi.org/10.2136/vzj2006.0086.

Montaldo, N., and J. D. Albertson, 2001: On the use of the forcerestore SVAT model formulation for stratified soils. J. Hydrometeor., 2, 571-578, https://doi.org/10.1175/1525-7541 (2001)002<0571:OTUOTF $>2.0 . C O ; 2$.

Moureaux, C., E. Ceschia, N. Arriga, P. Béziat, W. Eugster, W. L. Kutsch, and E. Pattey, 2012: Eddy covariance measurements over crops. Eddy Covariance: A Practical Guide to Measurement and Data Analysis, M. Aubinet, T. Vesala, and D. Papale, Eds., Springer Atmospheric Sciences Series, Vol. 2, Springer, 319-332.

Noilhan, J., and S. Planton, 1989: A simple parameterization of land surface processes for meteorological models. Mon. Wea. Rev., 117, 536-549, https://doi.org/10.1175/1520-0493 (1989) $117<0536$ :ASPOLS > 2.0.CO;2.

_ mesocale modeling. J. Climate, 8, 206-223, https://doi.org/ 10.1175/1520-0442(1995)008<0206:GGSEFM > 2.0.CO;2.

_ isation scheme. Global Planet. Change, 13, 145-159, https:// doi.org/10.1016/0921-8181(95)00043-7.

Olioso, A., and Coauthors, 2002: SVAT modeling over the AlpillesReSeDA experiment: Comparing SVAT models over wheat fields. Agron. J., 22, 651-668, https://doi.org/10.1051/agro:2002054.
Pan, H., and L. Mahrt, 1987: Interaction between soil hydrology and boundary layer development. Bound.-Layer Meteor., 38, 185-202, https://doi.org/10.1007/BF00121563.

Seneviratne, S. I., D. Lüthi, M. Litschi, and C. Schär, 2006: Landatmosphere coupling and climate change in Europe. Nature, 443, 205-209, https://doi.org/10.1038/nature05095.

Sinclair, T. R., 2005: Theoretical analysis of soil and plant traits influencing daily plant water flux on drying soils. Agron. J., 97, 1148-1152, https://doi.org/10.2134/agronj2004.0286.

Tardieu, F., and W. J. Davies, 1993: Integration of hydraulic and chemical signalling in the control of stomatal conductance and water status of droughted plants. Plant Cell Environ., 16, 341-349, https://doi.org/10.1111/j.1365-3040.1993.tb00880.x.

van den Hurk, B., and Coauthors, 2016: LS3MIP (v1.0) contribution to CMIP6: The Land Surface, Snow and Soil moisture Model Intercomparison Project-Aims, setup and expected outcome. Geosci. Model Dev., 9, 2809-2832, https://doi.org/ 10.5194/gmd-9-2809-2016.

Vergnes, J.-P., B. Decharme, and F. Habets, 2014: Introduction of groundwater capillary rises using subgrid spatial variability of topography into the ISBA land surface model. J. Geophys. Res. Atmos., 119, 11065-11086, https://doi.org/10.1002/ 2014JD021573.

Verhoef, A., and G. Egea, 2014: Modeling plant transpiration under limited soil water: Comparison of different plant and soil hydraulic parameterizations and preliminary implications for their use in land surface models. Agric. For. Meteor., 191, 22-32, https://doi.org/10.1016/j.agrformet.2014.02.009.

Viterbo, P., and A. C. M. Beljaars, 1995: An improved land surface parametrization scheme in the ECMWF model and its validation. J. Climate, 8, 2716-2748, https://doi.org/10.1175/ 1520-0442(1995)008<2716:AILSPS > 2.0.CO;2.

Vrugt, J. A., C. J. F. ter Braak, H. V. Gupta, and B. A. Robinson, 2009: Equifinality of formal (DREAM) and informal (GLUE) Bayesian approaches in hydrologic modeling? Stochastic Environ. Res. Risk Assess., 23, 1011-1026, https://doi.org/ 10.1007/s00477-008-0274-y.

Zhou, S., R. A. Duursma, B. E. Medlyn, J. W. G. Kelly, and I. C. Prentice, 2013: How should we model plant responses to drought? An analysis of stomatal and non-stomatal responses to water stress. Agric. For. Meteor., 182-183, 204-214, https:// doi.org/10.1016/j.agrformet.2013.05.009. 